\title{
Single-Unit Firing in Rat Perirhinal Cortex Caused by Fear Conditioning to Arbitrary and Ecological Stimuli
}

\author{
Sharon C. Furtak, ${ }^{1}$ Timothy A. Allen, ${ }^{1}$ and Thomas H. Brown ${ }^{1,2}$ \\ Departments of ${ }^{1}$ Psychology and ${ }^{2}$ Cellular and Molecular Physiology, Yale University, New Haven, Connecticut 06520
}

\begin{abstract}
Pretraining lesions of rat perirhinal cortex (PR) severely impair pavlovian fear conditioning to a $22 \mathrm{kHz}$ ultrasonic vocalization (USV) cue. However, PR lesions are without significant effect when the cue is a continuous tone at the same or a lower frequency. Here we examined fear-conditioning-produced changes in single-unit firing elicited in rat PR by a $22 \mathrm{kHz}$ tone cue or a $22 \mathrm{kHz}$ USV cue. Chronic recording electrodes were introduced from the lateral surface of the skull. Altogether, 200 well isolated units were studied in 28 rats. Overall, $73 \%$ of the recorded single units (145 of 200 units) evidenced statistically significant firing changes in response to the tone or USV conditional stimulus (CS) after it had been paired several times with an aversive unconditional stimulus (US). Interestingly, 33\% of units (66 of 200 units) that were initially CS-unresponsive became CS-responsive after conditioning. After conditioning, there were two notable differences between single-unit responses elicited by the USV cue and those elicited by the tone cue. First, $11 \%$ of the units (14 of 123 units) recorded from the USV-conditioned group displayed a precisely timed increase in firing rate during the $260 \mathrm{~ms}$ interval in which the US had previously occurred. This US-timed response was unique to the USV-conditioned group. Second, the mean latency of cue-elicited firing was $\sim 30 \mathrm{~ms}$ longer in the USV-conditioned group than in the tone-conditioned group. These cue-specific differences in acquired firing latencies and acquired firing patterns suggest that spectrotemporal properties of a CS can control the essential circuitry or neurophysiological mechanisms underlying fear conditioning.
\end{abstract}

Key words: timing; medial temporal lobe; ultrasonic vocalization; amygdala; temporal encoding; auditory fear conditioning

\section{Introduction}

Pavlovian fear conditioning is rapid and persistent, properties that make it well suited for investigating the neurophysiological basis of associative learning and memory (Fanselow and LeDoux, 1999; LeDoux, 2000; Pare et al., 2004; Fanselow and Poulos, 2005). During fear conditioning, a conditional stimulus (CS) acquires the ability to elicit fear-related conditional responses (CRs), such as freezing behavior, after being paired with an aversive unconditional stimulus (US). Considerable evidence has been adduced in support of the hypothesis that the lateral nucleus of the amygdala (LA) is critically involved in the acquisition of fear-related CRs (Fanselow and LeDoux, 1999; LeDoux, 2000; Gale et al., 2004; Maren and Quirk, 2004; Maren, 2005).

Several studies have demonstrated that perirhinal cortex (PR), which is laterally adjacent to and reciprocally connected with LA, is also essential for normal CR acquisition to certain types of stimuli. For example, both pretraining and posttraining PR lesions or inactivations impair fear conditioning to contextual stimuli (Corodimas and LeDoux, 1995; Sacchetti et al., 1999; Tassoni et al., 1999; Bucci et al., 2000; Bucci et al., 2002; Sacchetti et al., 2002; Lindquist et al., 2004; Padlubnaya et al., 2006a). Ad-

\footnotetext{
Received April 12, 2007; revised Sept. 17, 2007; accepted Sept. 18, 2007.

This work was supported by National Institutes of Health Grant MH058405 and Yale University. We thank Dianna Kholodar-Smith for comments on this manuscript and Michael Domjan and Mark Laubach for useful discussion.

Correspondence should be addressed to Thomas H. Brown, Department of Psychology, Yale University, 2 Hillhouse Avenue, New Haven, CT 06520. E-mail: thomas.brown@yale.edu. DOI:10.1523/JNEUROSCl.1653-07.2007

Copyright $\odot 2007$ Society for Neuroscience $\quad$ 0270-6474/07/2712277-15\$15.00/0
}

ditionally, pretraining PR lesions impair auditory fear conditioning when the cue is a $22 \mathrm{kHz}$ ultrasonic vocalization (USV) (Lindquist et al., 2004; Padlubnaya et al., 2006a), whereas these lesions are without effect when the cue is a continuous tone (Romanski and LeDoux, 1992; Bucci et al., 2000; Lindquist et al., 2004; Padlubnaya et al., 2006a) (but see Sacchetti et al., 2002).

In rats with temporal or rhinal cortical damage, fear conditioning to tones is thought to be supported by direct thalamic projections to LA (Romanski and LeDoux, 1992; Doron and LeDoux, 2000; LeDoux, 2000). In general, the contributions of cortical processing to fear conditioning are still unclear (Cahill et al., 1999; Fanselow and LeDoux, 1999; Weinberger, 2004; Boatman and Kim, 2006). One hypothesis asserts that cortical processing is necessary for normal fear conditioning to "complex" but not "simple" stimuli (Yaniv et al., 2001; Lindquist et al., 2004; Yaniv et al., 2004). Compared with continuous tones, USVs are obviously more complex. In particular, USVs are temporally discontinuous, consisting of a "bout" or series of "calls," and the individual calls contain unique frequency and amplitude modulations (Barfield and Geyer, 1972; Blanchard et al., 1991; Brudzynski et al., 1993; Brudzynski, 2005; Allen et al., 2007a). It is worth mentioning that PR lesions and inactivations also impair fear acquisition and expression to olfactory and visual stimuli (Herzog and Otto, 1997; Otto et al., 2000; Schulz et al., 2004; Shulz-Klaus et al., 2005).

To understand better the role of PR in auditory fear conditioning, the present study examined cue-elicited single-unit activity before, during, and after delay fear conditioning to either a 
$22 \mathrm{kHz}$ continuous tone or a $22 \mathrm{kHz}$ USV. Continuous tones and USVs are respective exemplars of what Domjan and coworkers term "arbitrary" and "ecological" stimuli (Domjan et al., 2004). Rodent USVs have long been recognized as ethologically important social signals (Anderson, 1954; Sewell, 1967; Barfield and Geyer, 1972; Sales and Pye, 1974; Blanchard et al., 1991; Knutson et al., 2002; Brudzynski, 2005; Brudzynski and Holland, 2005). The first goal of the present study was to discover whether fear conditioning causes changes in CS-elicited firing in rat PR. If so, the second goal was to characterize the plasticity and to discover any cue-specific differences in firing that might point to differences in the essential underlying circuitry or neurophysiological mechanisms.

\section{Materials and Methods}

Subjects. This study used 28 experimentally naive male Sprague Dawley rats weighing 250-400 g. Each animal was singly housed on a $12 \mathrm{~h}$ light/dark cycle with ad libitum access to food and water. Animals were handled for $3 \mathrm{~d}$ before surgery. Experiments were conducted in accordance with the Society for Neuroscience policies and the Yale University Animal Resources Center guidelines on the care and use of animals.

Surgery. A single surgery was performed on each animal to implant both a recording and stimulating electrode (see below). Animals were anesthetized with a mixture of ketamine $(100 \mathrm{mg} / \mathrm{kg}$, i.p. $)$ and xylazine $(20 \mathrm{mg} / \mathrm{kg}$, i.p. $)$ and secured in a stereotaxic instrument. Body temperature was regulated with a heating pad $\left(37^{\circ} \mathrm{C}\right.$; Braintree Scientific, Braintree, MA). The skin above the dorsal surface of the skull was cut along the midline and the right lateral edge and pulled back to expose the skull. Four holes were drilled through the dorsal surface of the skull and threaded with stainless-steel anchor screws. A ground wire was attached to one of these screws and used as an electrical reference during singleunit recording.

An eight-channel recording electrode bundle (described below) was chronically implanted in PR from the lateral surface of the skull. This procedure was developed to minimize cortical damage and to improve the accuracy of electrode placements (Allen et al., 2007a). The lateral surface of the skull was exposed by pulling the temporal muscle away from the skull with tissue spreaders. A $2 \mathrm{~mm}$ trephination was made at the intersection of the zygomatic arch, the parietal bone, and the temporal bone, exposing the temporal cortex just dorsal to PR. Two additional anchor screws were placed in the lateral surface of the skull on either side of the trephination. A micromanipulator drove the electrode bundle tip 1-2 $\mathrm{mm}$ into PR at a $45^{\circ}$ angle relative to the horizontal and coronal planes. Dental cement permanently secured the tip of the electrode bundle into place on the lateral surface. The electrode pin set was then cemented on the dorsal surface of the skull, anchored by the dorsal screws.

A bipolar stimulating electrode was inserted underneath the back skin, guided by stainless-steel tubing. The tips of the electrode were directed to the lumbar region bilaterally. Each tip was secured on either side of $(\sim 2$ $\mathrm{cm}$ from) the spine with a suture to the overlying skin. At the end of the implantation procedure, incisions were sutured and an antibiotic ointment was applied. Animals were given $10 \%$ acetaminophen in their drinking water (v/v; Silarx Pharmaceuticals, Spring Valley, NY) and allowed $72 \mathrm{~h}$ to recover.

Recording and stimulating electrode assembly. The design of the electrode assembly allowed the microwire bundle tip to be secured to the lateral surface of the skull, while placing the pin set in a vertical orientation on the dorsal surface of the skull (supplemental Fig. 1, available at www.jneurosci.org as supplemental material) (Allen et al., 2007a). Electrode bundles consisted of eight insulated tungsten microwires, $25 \mu \mathrm{m}$ in diameter (California Fine Wire, Grover Beach, CA). One end of each wire was stripped and secured to a 10-pin strip connector (Microtech, Boothwyn, PA). Conductive silver paint was applied to the pins to ensure good electrical connections. The other end was threaded through 30-gauge stainless-steel tubing, $5 \mathrm{~mm}$ in length. Excess wire was coated with latex between the stainless-steel tubing and the pin connector, providing protection and flexibility (supplemental Fig. 1, available at www.jneurosci.

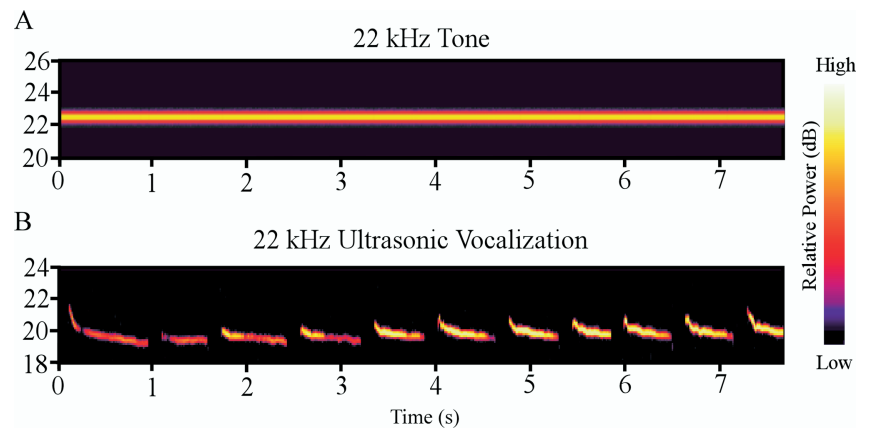

Figure 1. Spectrograms of the two auditory stimuli that were used as cues for fearconditioning. A, A $22 \mathrm{kHz}$ tone lasting $7.712 \mathrm{~s}$ ( $65 \mathrm{db}$ SPL). B, A $22 \mathrm{kHz}$ USV lasting $7.712 \mathrm{~s}(65 \mathrm{db}$ $\mathrm{SPL}$ ). The bout of 11 calls is centered at $\sim 19 \mathrm{kHz}$ (range, 19-22 kHz). The mean $\pm \mathrm{SE}$ call duration was $575 \pm 44.4 \mathrm{~ms}$, and the mean intercall interval was $132 \pm 1.5 \mathrm{~ms}$.

org as supplemental material). Before implantation, the bundle tip was cut at a $45^{\circ}$ angle $\sim 2 \mathrm{~mm}$ from the guide tubing. The typical tip resistance ranged from 150 to $300 \mathrm{k} \Omega$, measured at $1000 \mathrm{~Hz}$ (Impedance Check Module; Frederick Haer Company, Bowdoinham, ME). There was no electrical continuity among wires.

For the stimulating bipolar electrode, two 6-inch Teflon-coated stainless-steel wires ( $0.25 \mathrm{~mm}$ diameter; A-M Systems, Carlsborg, WA) were connected to two pins of a strip connector (Microtech). Protection and insulation was achieved with polyethylene tubing (Intramedic PE90; BD Diagnostic Systems, Sparks, MD). The terminal $4 \mathrm{~mm}$ of the stimulating wires were stripped of insulation.

Electrophysiological recordings. Recordings and fear conditioning were done in a Plexiglas observation chamber that was enclosed in a soundattenuating Faraday chamber. Pin sets were attached to a unity-gain head stage and commutator that passed the signal to a preamplifier $(15,000 \times$ gain; high- and low-pass filtered at $154 \mathrm{~Hz}$ and $13 \mathrm{kHz}$, respectively; Plexon, Dallas, TX). The signal was then processed by a Multichannel Acquisition Processor (Plexon), which allowed real-time thresholding and waveform discrimination (SortClient; Plexon). Electrical activity was also monitored with a digital oscilloscope (TDS 30334; Tektronix, Richardson, TX). Single units that had a signal-to-noise ratio (peak-topeak signal divided by the root mean square of the noise) of at least 5:1 were stored for additional off-line analysis. Cluster cutting techniques were used with principle components, spike width, and spike amplitude to isolate individual waveforms (Offline Sorter; Plexon). Autocorrelograms were also used to examine single-unit isolations (supplemental Fig. 1, right, available at www.jneurosci.org as supplemental material). Cross-correlograms between single units recorded on different wires were used to reduce possible redundancy.

Auditory stimuli. One of two auditory stimuli was used as a CS: a continuous $22 \mathrm{kHz}$ tone [ $10 \mathrm{~ms}$ rise time, $7.712 \mathrm{~s}$ duration, $65 \mathrm{db}$ sound pressure level (SPL)] (Fig. $1 A$ ) or a $22 \mathrm{kHz}$ USV that was pre-recorded from a conspecific (7.712 s duration, $65 \mathrm{db}$ SPL) (Fig. $1 B$ ). The USV contained 11 calls (Fig. $1 B$ ). Auditory stimuli were presented free field with an Enhanced Real-Time Processor RP2.1 [Tucker Davis Technologies (TDT), Alachua, FL] and electrostatic speakers (ED1; TDT) located on the top of a Plexiglas chamber, $\sim 50 \mathrm{~cm}$ from the floor. Loudness measurements were made at floor level using an ultrasonic decibel meter (Ultraprobe 9000; UE Systems, Elmsford, NY). The tones were produced with digital-tone-generator software (RPvds; TDT) in conjunction with an Enhanced Real-Time Processor RP2.1 (TDT).

The pre-recorded $22 \mathrm{kHz}$ USV was elicited from a naive rat by an unsignaled foot shocks delivered through a grid floor (1 s, $1 \mathrm{~mA}$; Coulbourn Instruments, Lehigh Valley, PA). USVs were digitally recorded (RP2.1; TDT) and stored on a computer (100 kHz sampling rate, $32 \mathrm{bit).}$ The recorded USV was played back to subjects through the RP2.1 and ED1. So-called " $22 \mathrm{kHz}$ USVs," which actually can range in frequency from 18 to $32 \mathrm{kHz}$, are commonly produced by rats in response to aversive or threatening stimuli, by stimuli (contexts or cues) that have been associated with aversive or threatening stimuli, or after ejaculation 
(Barfield and Geyer, 1972; Blanchard et al., 1991; van der Poel and Miczek, 1991; Brudzynski et al., 1993; Choi and Brown, 2003; Brudzynski, 2007; Litvin et al., 2007). Twenty-two kHz USVs have been measured as defensive CRs (Lee et al., 2001; Choi and Brown, 2003; Koo et al., 2004; Moyer and Brown, 2006) and used as CSs in fear-conditioning paradigms (Lindquist et al., 2004; Padlubnaya et al., 2006a).

Somatosensory stimulus. The bipolar stimulating electrode was used to deliver an aversive US. The bipolar stimulating electrode was designed to isolate the current density away from the single-unit electrodes, thereby allowing simultaneous recordings during shock presentations in preexposure and conditioning trials. The back-shock stimulus consisted of six shocks ( $10 \mathrm{~ms}, 5 \mathrm{~mA}$ ) at $20 \mathrm{~Hz}$ delivered via a constant-current generator (BSI-2; Bak Electronics, Mount Airy, MD). Although we did not quantify the magnitude of the unconditional behavioral responses to the somatosensory stimulus, it is worth noting that each shock elicited a brief scurry around the chamber, typically followed by freezing seconds later. Overall, the response to a back shock was very similar to what we observe in response to a grid-floor shock.

Behavioral procedures. Fear conditioning consisted of three stages: preexposure, conditioning, and testing/extinction. The three stages were recorded with a miniature IR-CCD camera (Circuit Specialists, Mesa, AZ) connected to a video cassette recorder for later off-line behavioral analysis. During the preexposure stage, most of the animals (21 of 28) received pseudoconditioning trials in which the US was explicitly unpaired with the CS (10 CS and US presentations). The CSs and USs were presented in random order with a $90 \pm 30 \mathrm{~s}$ interval between stimuli. A subset of animals (7 of 28) instead received $10 \mathrm{CS}$-alone preexposure trials in which the CS to CS intervals were $180 \pm 60 \mathrm{~s}$. The US was omitted in this group to eliminate any pairing-independent effects on responses to the cues. Possible evidence of sensitization or context conditioning was examined within and between groups. Among the seven animals that received CS-alone preexposure trials, the degree of shock responsiveness was determined during the conditioning stage when the back shock was presented.

Immediately after preexposure, subjects were given 20 conditioning trials in which the CS always coterminated with a brief back-shock US. The interstimulus interval (ISI) was $7.452 \mathrm{~s}$, and the inter-trial interval was $120 \pm 60 \mathrm{~s}$. After conditioning trials, subjects were returned to their home cages in the animal vivarium. At least $4 \mathrm{~h}$ later, they were brought back to the original conditioning context. After a 2 min baseline period, each animal received $40 \mathrm{CS}$-alone test trials (ISI, $15 \pm 5 \mathrm{~s}$ ) in which freezing served as the CR (Blanchard and Blanchard, 1969). Time spent freezing was scored by a blind observer on a continuous minute-byminute basis with the aid of a stop watch. For each animal, the percentage freezing was calculated, for each minute, by dividing the total time freezing (in seconds) by 60. For this initial study of conditioning effects on PR single-unit responses, we decided not to use a context shift because of known and unknown complications that might arise in connection with contextual control of cue-elicited single-unit activity (Hobin et al., 2003). One suspects that some of the cue-specific conditioning effects reported here may depend on the conditioning context. Context shifts would certainly be worth exploring, because PR is known to be critical for context conditioning (Bucci et al., 2000, 2002; Lindquist et al., 2004; Padlubnaya et al., 2006a).

Classification of firing patterns. The classification scheme, which was based on firing patterns that are commonly elicited by auditory stimuli in other brain regions (Heil, 1997; Chimoto et al., 2002), was intended to be as simple as possible and yet still capture some potentially important differences between stimuli and among units. Stimulus-elicited firing patterns were classified along three axes (Allen et al., 2007a) according to whether they entailed (1) an increase or decrease in firing frequency, (2) a phasic or a tonic firing change, and (3) firing in response to the stimulus onset or offset. Not all possible logical combinations were observed. Among the firing patterns that were actually observed, the four simplest ones were designated as follows: phasic onset $(+)$, a transient increase in the firing rate to the stimulus onset; phasic offset $(+)$, a transient increase in firing rate to the stimulus offset; tonic $(+)$, a sustained increase in firing rate during the stimulus presentation; and tonic $(-)$, a sustained decrease in firing rate during the stimulus presentation. A subtype of phasic onset $(+)$ firing consisted of phasic $(+)$ responses to successive calls of a USV. Elsewhere, this subtype was termed a "call-related" firing pattern (Allen et al., 2007a).

Other observed firing patterns, which consisted of combinations of the simpler ones, included the following three: phasic onset $(+) /$ offset $(+)$, a transient increase in firing rate to both the stimulus onset and offset; phasic onset $(+) /$ tonic $(+)$, a transient increase in firing rate to the stimulus onset with a smaller but significant increase in the sustained firing rate during the entire stimulus presentation; and phasic onset $(+) /$ tonic (-), a transient increase in firing rate to the stimulus onset and a sustained firing rate decrease during the remainder of the stimulus presentation. The application of this classification scheme is further elucidated in Results.

Because the somatosensory stimulus was so brief $(260 \mathrm{~ms})$, no distinction was made between firing to the onset or offset of the stimulus or between tonic and phasic patterns of firing. Responses to the somatosensory stimulus were most distinguishable based on the duration of the increased firing. The firing patterns elicited by the back shock were categorized into either a short-duration or a long-duration increase in firing rate. Short-duration responses were operationally defined as a statistically significant increase in firing rate that lasted $<250 \mathrm{~ms}$ (from 0 to 250 $\mathrm{ms}$ ). Long-duration responses, which could last several seconds after the shock presentation, were operationally defined as a statistically significant increase firing rate during both the first $250 \mathrm{~ms}$ (from 0 to $250 \mathrm{~ms}$ ) and the next $250 \mathrm{~ms}$ (from 250 to $500 \mathrm{~ms}$ ) after the presentation of the back shock.

Statistical analysis. Graphical and statistical analyses were performed with NEX software (Plexon), custom-made Microsoft (Seattle, WA) Excel spreadsheets; R 2.3.0 (http://www.r-project.org/), and SPSS 14.0 (SPSS, Chicago, IL). To classify the auditory stimulus-elicited firing pattern, 10 planned $t$ tests were performed on each unit that compared its spontaneous baseline firing rate with its firing rate during a specific time bin during or immediately after the presentation of the stimulus. Unless specifically indicated otherwise, a Bonferroni's correction was used to give a familywise $\alpha<0.05$. This conservative correction reflects our interest in larger effect sizes plus the need for multiple $t$ tests to explore different types of firing patterns. When any one of the $t$ tests was significant, the single unit was classified as "responsive." Responsive units were then subclassified, in terms of type of CS-elicited firing pattern, based on which $t$ tests were significant (see above, Classification of firing pattern). Two-tailed tests were used because the firing rate might increase or decrease. Bonferroni's corrections were not applied to follow-up aggregate analyses of units that were classified as "unresponsive." Because any possible effects were already known to be small, the emphasis was on statistical power rather than protection against $\alpha$ errors.

Spontaneous (baseline) single-unit activity was defined by the average firing rate during the $5 \mathrm{~s}$ period just before the presentation of the auditory stimulus. Phasic onset $(+)$ and phasic offset $(+)$ responses were tested for statistical significance within the first four time bins (first 200 ms) after the auditory stimulus onset or offset, respectively, compared with the spontaneous baseline firing rate. Tonic responses were tested for statistical significance by comparing the average firing rate throughout the auditory stimulus presentation (7.712 s) with the average spontaneous baseline firing rate. A Welsch-Satterwaite solution was used to correct the degrees of freedom for unequal sample sizes. This correction was made because there were more time bins during the stimulus presentation (which lasted $7.712 \mathrm{~s}$ ) than during the baseline period (which lasted $5 \mathrm{~s})$.

Shock-elicited firing was examined using $t$ tests for dependent samples that compared the mean firing rate during each of the first five $50 \mathrm{~ms}$ time bins after the shock with the mean spontaneous baseline firing rate during the $5 \mathrm{~s}$ period before the stimulus presentation. During the testing stage of the experiment, this same analysis examined the presence of a "US-timed" response. An additional $t$ test was conducted to classify a shock-responsive unit as giving either a short-duration or a longduration response (see above, Classification of firing pattern). This additional $t$ test compared the average firing rate in the five time bins in the next $250 \mathrm{~ms}$ period after the shock to the spontaneous baseline firing rate. 
Visual confirmation of all response patterns was based on perievent raster plots and histograms with a $50 \mathrm{~ms}$ bin width.

CS-elicited firing patterns were analyzed during the preexposure phase, the conditioning phase, and the testing phase. Each "plastic" unit was classified according to whether it became CS responsive, became CS unresponsive, changed firing pattern, or maintained firing pattern and changed firing frequency. Units that were classified as maintaining the same firing pattern were further analyzed for changes in firing frequency between experimental stages using ANOVA. Each "nonplastic" unit was classified according to whether it maintained its firing pattern and firing frequency or was CS unresponsive during all stages of the experiment. Log-likelihood ratio tests ( $G$ tests) (Sokal and Rohlf, 1995) analyzed differences in the proportions of units in various response categories or experimental conditions. Trends in spontaneous firing across conditioning trials were examined using ANOVAs (stage $\times$ group).

Firing latency measurements were based on histograms with a $10 \mathrm{~ms}$ bin width. Latencies were defined by the first time bin, after the stimulus presentation, to show a statistically significant change in firing rate compared with the rate during the preexposure stage of the experiment. Latencies are reported throughout as midpoints or limits of the appropriate time bins and sometimes as the range of time bins. Two types of plots of "aggregate" responses were constructed. In the first type, $Z$ scores were calculated to facilitate comparisons with previous studies in LA (Repa et al., 2001; Hobin et al., 2003). In these plots, the firing level for each unit and time bin was transformed as follows:

$$
Z=\left(R_{\mathrm{A}}-R_{\mathrm{B}}\right) / S_{\mathrm{B}},
$$

where $R_{\mathrm{A}}$ is the firing rate in a given time bin after the presentation of the auditory stimulus, $R_{\mathrm{B}}$ is the mean firing rate averaged across the $5 \mathrm{~s}$ baseline period immediately before the presentation of the auditory stimulus, and $S_{\mathrm{B}}$ is the $\mathrm{SD}$ of the firing rate during the baseline period. For graphical purposes, mean $Z$ scores were calculated for each time bin and plotted as a function of time. Probabilistic inferences regarding changes in mean $Z$ scores were based on two-tailed $t$ tests. The second type of aggregate plot was based on percentage changes in the firing rate as a function of time. For each neuron and time bin, a percentage change was calculated as follows:

$$
P=\left(R_{\mathrm{A}} / R_{\mathrm{B}}\right) \times 100 \%,
$$

where $R_{\mathrm{A}}$ and $R_{\mathrm{B}}$ are defined as above. The mean value of $P$ was plotted against time.

The behavioral CR (freezing) was explored using a two-way ANOVA, with one within-subjects factor (time) and one between-subjects factor (USV vs tone group). Extinction was assessed using dependent $t$ tests that compared freezing during the first and last minute of the testing/extinction session. Pearson's bivariate correlation quantified the linear association of extinction of freezing with time.

Histological determination of recording site. At the end of the recording sessions, subjects were given an overdose of sodium pentobarbital (100 $\mathrm{mg} / \mathrm{kg}$, i.p.) and a small marking lesion was made by passing current between two of the recording wires (3-5 s, $50 \mu \mathrm{A}$ direct current; Lesion Maker; Grass Instruments, Quincy, MA). The animals were transcardially perfused with $0.1 \mathrm{~m}$ PBS, followed by $4 \%$ paraformaldehyde. Brains were removed and placed in $4 \%$ paraformaldehyde for $24 \mathrm{~h}$ and cryoprotected in $30 \%$ sucrose for at least $3 \mathrm{~d}$. Horizontal sections $(70 \mu \mathrm{m})$ were sliced with a freezing microtome, mounted on gelatin-coated slides, and Nissl-stained with cresyl violet. Brain sections were examined under a Zeiss (Thornwood, NY) Axioskop light microscope to determine the location of the marking-lesion site.

\section{Results}

\section{Number, persistence, and waveforms of PR units}

A total of 200 well isolated PR units were analyzed in 28 rats. The analysis only included units that were recorded throughout all three stages of the experiment (for $6-7 \mathrm{~h}$ from the beginning of the preexposure period). Figure $2 A$ illustrates three sets of superimposed waveforms $(\sim 1000$ each $)$ from the same unit in the
A
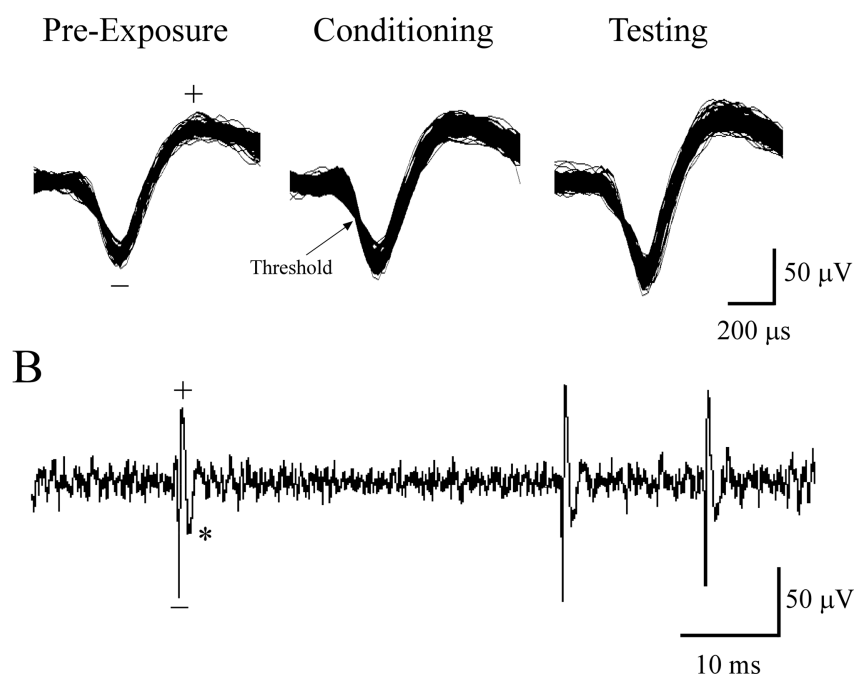

Figure 2. A representative PR unit illustrated on two different timescales. $\boldsymbol{A}$, Superimposed voltage waveforms from the preexposure, conditioning, and testing phases of the experiment. The indicated threshold voltage (arrow) triggered the capture of $1 \mathrm{~ms}$ time segments (300 $\mu \mathrm{s}$ before the threshold crossing and $700 \mu$ s after the threshold crossing) that were used off-line for single-unit analysis. Characteristically, an initial negative phase was followed by a positive phase. $\boldsymbol{B}$, A portion of an oscilloscope trace showing spontaneous firing in the same unit during the intertrial interval of the conditioning stage of the experiment. This timescale shows that the positive phase of the voltage waveform was followed by a smaller and more prolonged negative phase (to the left of the asterisk).

preexposure period (left), the conditioning period (middle), and the testing period (right). These waveforms include the $1 \mathrm{~ms}$ time segment that was digitized for subsequent off-line analysis. The illustrated waveform is typical in that an initial negative phase is followed by a positive phase. In some cases, the large negative phase was preceded by a small positive phase, and, in others, the entire waveform was narrower. The narrower waveforms may reflect activity in "fast-spiking" PR neurons that are thought to be inhibitory (Faulkner and Brown, 1999; McGann et al., 2001; Moyer et al., 2002; Moyer and Brown, 2007). Figure $2 B$ shows spontaneous firing in the same unit during the intertrial stage of conditioning. The longer time segment reveals that the large positive phase of the waveform was followed by a much smaller and more prolonged negative phase, identified in Figure $2 B$ by the asterisk. This triphasic waveform is representative of most of the PR units included in the present analysis.

\section{Histological determination of recording sites}

Nissl-stained brain sections verified that all recording tips were within the boundaries of PR (Burwell et al., 1995; Burwell and Amaral, 1998; Burwell, 2001; Furtak et al., 2007b). The reliability of the lateral implantation procedure in targeting PR (Allen et al., 2007a) was attributable to the fact that temporal cortex was directly visualized during the implantation. Marking lesions were most frequently in layers II/III and V of PR. The locations of the electrode tips ranged from -4.0 to $-6.0 \mathrm{~mm}$ (anteroposterior) and -6.8 to $-7.6 \mathrm{~mm}$ (dorsoventral) relative to bregma (Fig. $3 A$ ). Figure $3 B$ shows an example of a representative marking lesion in a horizontal section that corresponds to Plate 98 of the Paxinos and Watson rat atlas (1998). Cortical damage was minimized (Fig. 3B) because of the short distance traveled by the microwire bundles and because this short distance eliminated the need to insert a microwire guide tube into the brain. 
A
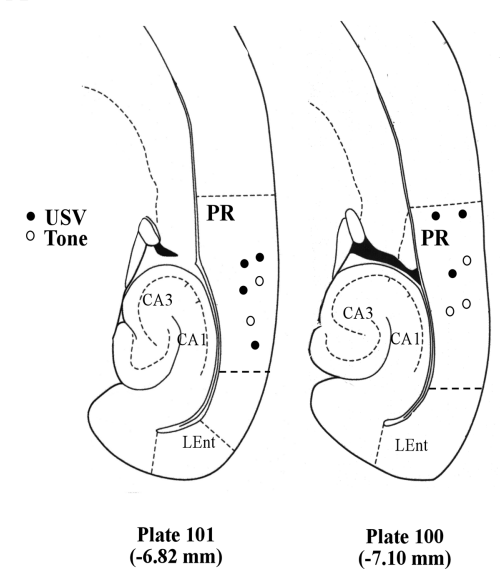

$\mathrm{B}$
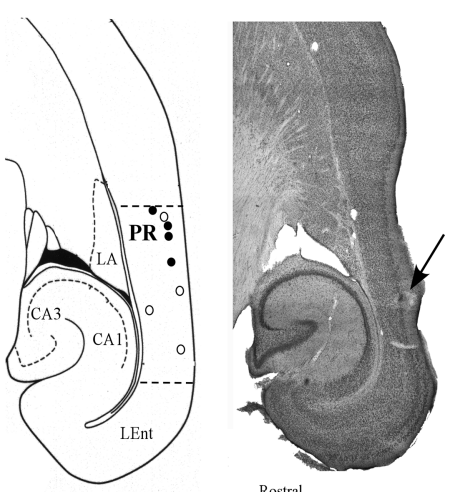

$\underset{(-7.60 \mathrm{~mm})}{\text { Plate } 98} \overbrace{\text { Caudal }}^{\text {Moteral }}$

Figure 3. Horizontal sections showing the location of recording sites within perirhinal cortex. A, Placements of 28 electrode bundles are mapped onto stereotaxic plates adapted from the atlas of Paxinos and Watson (1998). Results were combined from subjects conditioned to the USV (filled circles; $n=15$ rats) and the tone (open circles; $n=13$ rats) cues. Dorsoventral locations of plates 98 -101 show the depth relative to bregma. CA1, Area CA1 of the hippocampal formation; CA3, area CA3 of the hippocampal formation; LEnt, lateral entorhinal cortex. $\boldsymbol{B}, \mathrm{A}$ representative marking lesion, indicated by the arrow, made at the tip of an electrode bundle. The $70 \mu \mathrm{m}$ horizontal section was stained for Nissl with cresyl violet.

Table 1. Distribution of unconditional firing patterns to auditory and somatosensory stimuli as a function of CS group

\begin{tabular}{lccc}
\hline CS- and US-elicited firing patterns & USV group & Tone group & Combined \\
\hline CS-elicited & & & \\
Phasic onset (+) & 30 of $123(24 \%)$ & 22 of $77(29 \%)$ & 52 of $200(26 \%)$ \\
Phasic offset (+) & 0 of 123 & 4 of $77(5 \%)$ & 4 of $200(2 \%)$ \\
Tonic (+) & 5 of $123(4 \%)$ & 6 of $77(8 \%)$ & 11 of $200(6 \%)$ \\
Tonic (-) & 1 of $123(1 \%)$ & 1 of $77(1 \%)$ & 3 of $200(2 \%)$ \\
Phasic onset/offset (+) & 0 of 123 & 6 of $77(8 \%)$ & 6 of $200(3 \%)$ \\
Phasic onset (+)/tonic (+) & 10 of $123(8 \%)$ & 12 of $77(16 \%)$ & 22 of $200(11 \%)$ \\
Phasic onset (+)/tonic (-) & 2 of $123(2 \%)$ & 0 of 77 & 1 of $200(1 \%)$ \\
Total CS-responsive neurons & 48 of $123(39 \%)$ & 51 of $77(66 \%)$ & 99 of $200(50 \%)$ \\
US-elicited & & & \\
Short-duration & 55 of $123(45 \%)$ & 48 of $77(62 \%)$ & 103 of $200(52 \%)$ \\
Long-duration & 39 of $123(32 \%)$ & 15 of $77(19 \%)$ & 54 of $200(27 \%)$ \\
Total US-responsive neurons & 94 of $123(76 \%)$ & 63 of $77(82 \%)$ & 157 of $200(79 \%)$ \\
\hline
\end{tabular}

\section{Spontaneous single-unit activity}

The mean spontaneous firing rates (in 200 units from 28 animals) across the three stages of the experiment were as follows: preexposure $(3.87 \pm 0.33 \mathrm{~Hz})$; conditioning $(3.89 \pm 0.34 \mathrm{~Hz})$; and testing $(4.27 \pm 0.34 \mathrm{~Hz})$. These rates are somewhat higher than those reported in LA $(<1 \mathrm{~Hz})$ (Quirk et al., 1995, 1997) and slightly lower than rates reported in temporal cortex $(\sim 5 \mathrm{~Hz})$ (Quirk et al., 1997; Armony et al., 1998). ANOVA revealed no significant main effect of stage of experiment $(p>0.05)$ and no significant stage $\times$ CS group interaction $(p>0.05)$.

Pooling the data from all three stages revealed no significant main effect of CS group ( $p>0.05)$. For additional analysis, the results from the two preexposure conditions (CS-alone vs unpaired CS and US presentations) were separated. A CS-alone preexposure group (seven subjects) was compared with the group that received unpaired CS and US presentations (21 subjects) before conditioning. A two-way ANOVA revealed no significant main effect of preexposure condition and no significant interaction between stage of experiment and preexposure condition $(p>0.05)$. Thus, unpaired US presentations had no detectable effect on spontaneous activity.

\section{CS- and US-elicited firing patterns before conditioning}

Table 1 summarizes the distribution of unit responsiveness, before conditioning, as a function of the eliciting stimulus and the elicited firing pattern. Overall, half of the units were auditory responsive before conditioning. Of the 123 neurons recorded from the USV CS group, 39\% (48 of 123 neurons) responded to the presentation of the USV before to conditioning. Sixty-six percent of the cells (51 of 77) responded to the $22 \mathrm{kHz}$ tone. There was a significant difference in the proportion of units that were responsive to the USV versus the tone $\left(G_{(1)}=4.56 ; p<0.05\right)$.

Seven different firing patterns were observed in response to the two auditory stimuli (Fig. 4). The USV sometimes elicited a call-related firing pattern (Allen et al., 2007a) (Fig. 5) that might be regarded as an eighth pattern. However, in Table 1, it was simply classified as a phasic onset $(+)$ response. The reason for this classification is evident in the three-dimensional (3D) plot in Figure 5B, which aligns singleunit activity to the onsets of each call. The ridge of this $3 \mathrm{D}$ contour reveals a series of phasic onset $(+)$ responses to successive calls. Note that the call-related firing pattern caused a hint of periodicity in the histogram (Fig. 5A). There was no significant difference $(p>0.05)$ between the two preexposure groups (CS-alone or unpaired) in the proportion of auditory-responsive PR units. For additional analysis, two preexposure groups were combined.

Seventy-nine percent of the units were responsive to the back-shock stimulus (Table 1). Figure 6 shows examples of short- and long-duration US-evoked firing patterns. In the example illustrated in Figure $6 B$, firing persisted throughout the entire $5 \mathrm{~s}$ of postshock recording. Firing that outlasts the initiating stimulus has also been reported in PR neurons in brain slices exposed to a cholinergic agonist (Leung et al., 2006). Interestingly, $40 \%$ of PR units ( 80 of 200) were responsive to both the somatosensory stimulus and the auditory stimulus. This extensive neurophysiological convergence of auditory and somatosensory information in PR accords well with neuroanatomical findings (Shi and Cassell, 1997; Burwell and Amaral, 1998; Linke, 1999; Shi and Cassell, 1999; Burwell, 2000; Doron and LeDoux, 2000; Kimura et al., 2003; Furtak et al., 2007a).

\section{Conditioning-produced changes in CS-elicited firing}

Single units were classified as being plastic if CS-evoked firing, after CS-US pairings, was significantly different from CS-elicited firing during the preexposure trials. Conditioning-produced plasticity was subdivided into five types of changes (Table 2) (cf. Bures and Burresova, 1970). These included units that were (1) initially CS unresponsive but became CS responsive, (2) initially CS responsive but became CS unresponsive, $(3,4)$ initially CS responsive but increased or decreased firing rate, while maintain- 
ing the same firing pattern; or (5) initially CS responsive and changed firing pattern (Table 2). Conditioning-produced changes were observed in all seven types of unconditional response firing patterns (Figs. 4, 5) that were elicited by the two cues. A unit was classified as nonplastic if (1) the CS-evoked activity was unchanged in firing pattern and firing frequency throughout all stages of fear conditioning or (2) the unit was not significantly responsive to the CS at any stage of the experiment. Table 2 summarizes the number of units from the tone and USV groups that were classified as plastic or nonplastic as just described. The proportion of cells in each category was not significantly affected by analyzing only the first 20 testing trials instead of all 40 trials ( $p$ values $>$ $0.05)$. Overall, $73 \%$ of PR units were classified as plastic.

In the USV group, $67 \%$ of the neurons (83 of 123) showed significant changes in CS-elicited firing after CS-US pairings (Table 2) and were thus categorized as plastic. The remaining 33\% were classified as nonplastic (40 of 123) (Table 2). There were significant differences in the proportions of the five different types of plasticity $\left(G_{(4)}=84.11 ; p<0.001\right)$. The most prevalent type of firing change in the USV group was from CS unresponsive to CS responsive $(34 \% ; 42$ of 123$)$ (Table 2$)$. Figure $7 A$ shows the perievent raster plots and histograms of a unit that was unresponsive to the USV during the preexposure period but acquired a phasic onset $(+)$ response during conditioning. The acquired onset response was evident in both the conditioning period (Fig. $7 A$, middle) and the testing session (Fig. 7A, bottom). This same unit also acquired a small but statistically significant phasic $(+)$ response at the former time of the US (Fig. 7A, bottom). During the conditioning period, US-elicited firing precluded detection of any CS-elicited firing changes that might have occurred in this time interval (Figs. 6, 7A). This US-timed response is further discussed below. The second most common modification in the USV group was a change in the elicited firing pattern (19\%; 23 of 123) (Table 2). The unit illustrated in Figure $8 B$ is an example of a conditioning-produced firing-pattern change. In the preexposure period, the unit gave a phasic onset $(+)$ response during the first call of the USV. In the testing period, the unit retained the phasic onset $(+)$ response during the first call and acquired a US-timed response during the 11th and final call of the USV.

In the tone group, $82 \%$ (63 of 77 ) of the units exhibited conditioning-produced plasticity (Table 2 ) and were thus categorized as plastic. There were significant differences in the proportions of different types of changes $\left(G_{(4)}=80.16 ; p<0.001\right)$. In contrast to the USV group, the most common type of plasticity in the tone group entailed a change in firing pattern $(43 \% ; 33$ of 77) (Table 2). Most commonly, the change was from a phasic onset $(+)$ firing pattern to a phasic onset/offset $(+)$ pattern. The second most prevalent type of plasticity, changing from CS unresponsive to CS responsive, occurred in $31 \%$ of the units in the tone group (24 of 77) (Table 2). The units shown in Figures $7 B$ and $9 A$ were unresponsive to the tone during the preexposure period but exhibited a phasic onset $(+)$ response during the conditioning and testing periods. Overall, there was no significant difference between the two cue groups in the proportion of plastic units (Table 2) $(p>0.05)$.

\section{CS-specific differences in elicited firing after conditioning}

Although there were obvious similarities between the two cues, in terms of the types of conditioning-produced changes they elicited (Table 2), the US-timed response was only observed in the USV group (Fig. 8), in which it occurred in 11\% (14 of 123) of the units. An instance of US-timed firing occurred in 7 of the 15 animals in the USV-conditioned group. The incidence in each of these seven animals was, in ascending order, 1, 1, 2, 2, 2, 2, and 4. Figure $8 \mathrm{~A}$ shows an aggregate response from all 14 units that exhibited this change. The ordinate of the aggregate plot is the mean percentage score (from Eq. 2) in the 14 units that exhibited a statistically significant, US-timed response. Before conditioning, the firing rate was relatively constant during the last $512 \mathrm{~ms}$ of the USV presentation (Fig. 8A, Pre-exposure, blue-shaded squares). After conditioning, there was a significant increase in the firing rate during the $260 \mathrm{~ms}$ time interval that previously contained the US (Fig. $8 \mathrm{~A}$, red-shaded bars). Interestingly, the peak firing occurred near the midpoint of this $260 \mathrm{~ms}$ interval (Fig. $8 \mathrm{~A}$, red-shaded bars).

US-timed firing emerged at $\sim 7.525 \mathrm{~s}$ from the USV onset, it peaked at $\sim 7.575 \mathrm{~s}$, and it decayed back to baseline levels by $\sim 7.675$ s. These numbers are based on the midpoints of the 
A

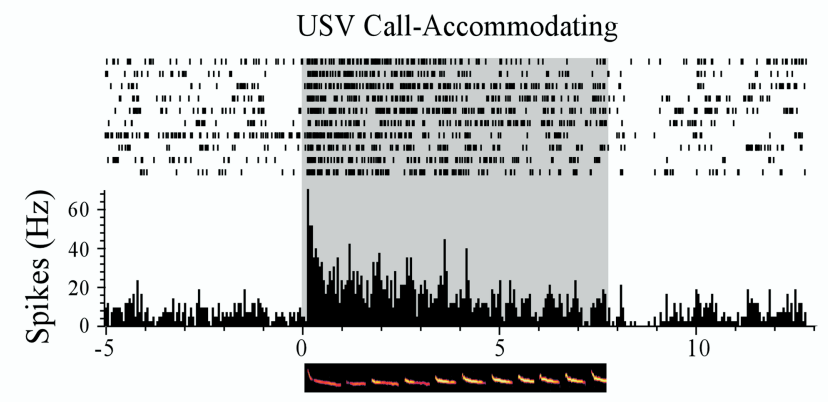

Time (s)

B

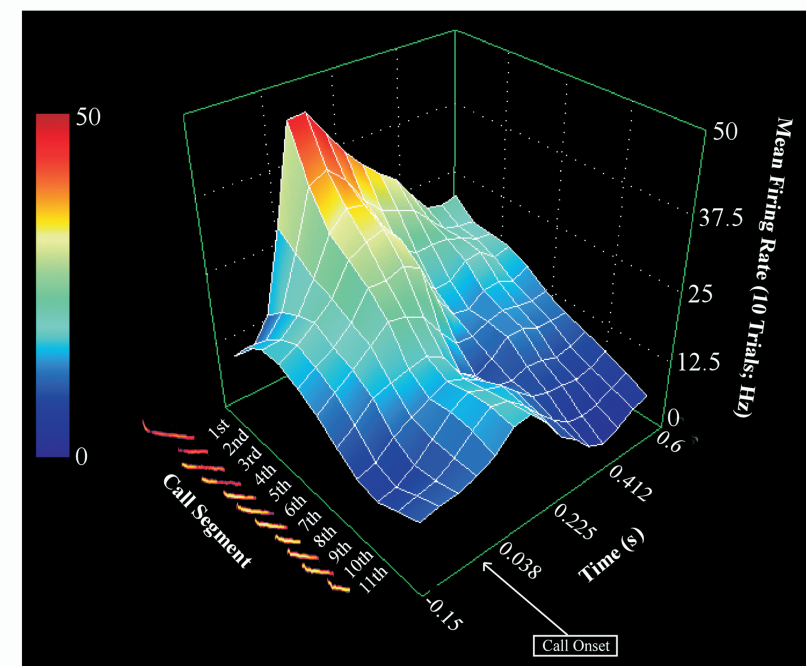

Figure 5. A call-related firing pattern elicited by a $22 \mathrm{kHz}$ USV. Time bins are $50 \mathrm{~ms}$. $A$, The raster plot and perievent histogram suggest a phasic onset $(+) /$ tonic $(+)$ response. The USV was present from 0 to $7.712 \mathrm{~s}$ (shaded area). The histogram hints at a degree of periodicity in the firing rate. The spectrogram of the USV is aligned and depicted underneath the time axis. $\boldsymbol{B}$, The three-dimensional contour plot reveals that the apparent periodicity in the histogram is associated with firing to the onsets of individual calls of the USV. There is a large increase in the firing rate to the onset of the first call (indicated by the red elevation) and a progressively smaller increase in the firing rate to the onsets of subsequent calls.

appropriate time bins (width, $50 \mathrm{~ms}$ ) (Fig. $8 \mathrm{~A}$ ). Recall that the USV duration was $7.712 \mathrm{~s}$ (Fig. $1 B$ ). Unlike unconditional responses to the shock (Fig. $8 A$, green-shaded circles), the UStimed responses did not persist beyond the interval that previously contained the shock (Fig. $8 \mathrm{~A}$, red-shaded bars). Overall, the US-timed response entailed a $448 \%$ increase in firing frequency (Fig. 8A) compared with the $5 \mathrm{~s}$ baseline period just before the stimulus onset. Before conditioning, 13 of the 14 units (93\%) that acquired a US-timed response were also shock responsive, and all 14 units (100\%) were USV responsive. During the preexposure period, 12 of the 14 units $(86 \%)$ gave a phasic onset $(+)$ response to the USV. In summary, the US-timed response was most likely to be acquired by multimodal units that initially gave a phasic onset $(+)$ response during the first call of the USV.

Three-dimensional contour plots (as in Fig. 5) are useful for visualizing the acquisition of a US-timed response. The contour in Figure $8 C$ illustrates a phasic onset $(+)$ response to the USV during the preexposure period. During this period, the unit only responded to the first of the 11 calls. The contour in Figure $8 D$ shows that, after conditioning, the unit acquired a US-timed response during the final call. Note that the contour has assumed a
A

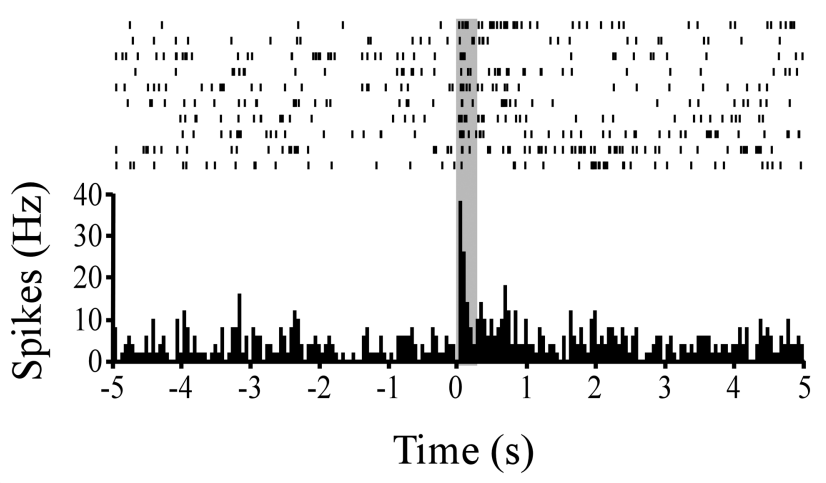

B

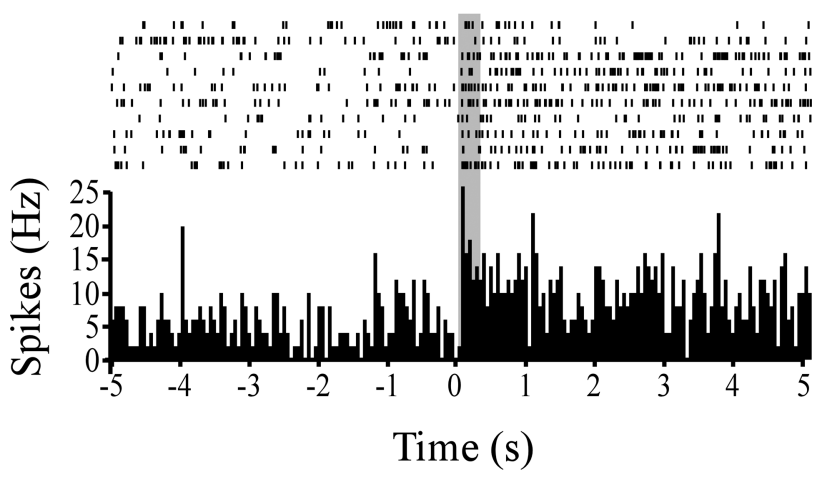

Figure 6. Two types of firing patterns elicited by the somatosensory stimulus. Six 10 ms back shocks were presented in the interval between 0 and $+0.26 \mathrm{~s}$ at $20 \mathrm{~Hz}$ (presence indicated by the gray shading). Time bins are $50 \mathrm{~ms}$. $\boldsymbol{A}, \mathrm{A}$ short-duration response, defined as a transient increase in firing rate ( $<250 \mathrm{~ms}$ ). $\boldsymbol{B}$, A long-duration response, defined as a more prolonged increase in firing rate ( $>250 \mathrm{~ms}$ ). This particular long-duration response persisted for the entire 5 s period of postshock recording.

distinctive saddle shape (Fig. $8 D$ ). The shape reflects the fact that the unit retained the original response to the first call and acquired a new response to the 11 th call (Fig. $8 D$ ). In the present sample of 200 PR units, saddle-shaped contours were never observed during the preexposure phase. Similarly, these contours were never observed in a previous sample of $142 \mathrm{PR}$ units (Allen et al., 2007a) recorded from animals that were never exposed to the US. One conditioning-produced change in firing pattern was unique to the tone group, in which $30 \%$ (23 of 77) of the units acquired a phasic offset $(+)$ response to the CS (Fig. 9). An instance of an acquired phasic offset $(+)$ response occurred in 10 of the 13 animals in the tone-conditioned group. The incidence in each of these 10 animals was, in ascending order, 1, 1, 1, 1, 1, 2, 2, 2,5 , and 7 . In sharp contrast to US-timed responses, acquired offset responses always occurred entirely after the CS offset. Figure $9 B$ shows an aggregate plot of the 23 units that exhibited this change. The ordinate of the aggregate plot is the mean percentage score (Eq. 2) in the 23 units that acquired a phasic offset $(+)$ response. In interpreting Figure 9, recall that the tone duration was $7.712 \mathrm{~s}$ (Fig. 1A). The acquired offset response emerged at $\sim 7.775 \mathrm{~s}$ from the tone onset, it peaked at $\sim 7.875 \mathrm{~s}$, and it decayed back to baseline levels by $\sim 7.975 \mathrm{~s}$. These numbers are based on the midpoints of the appropriate time bins (bin width, $50 \mathrm{~ms}$ ) (Fig. 9B). Overall, the acquired offset response entailed a $344 \%$ increase in firing frequency relative to the $5 \mathrm{~s}$ baseline period (Fig. 9B).

Note that phasic offset $(+)$ responses were sometimes elic- 
ited by the tone before conditioning (Fig. 2B). However, before conditioning, none of the 23 units that acquired a phasic offset $(+)$ response evidenced significant firing during the time period of the offset response. Figure $9 A$ shows the raster plots and histograms of a unit that acquired a phasic offset $(+)$ response. During the conditioning stage, US-elicited firing precluded detection of any acquired offset responses to the CS (Fig. 9A, middle). During testing, the unit exhibited a significant phasic offset $(+)$ response as well as a significant phasic onset $(+)$ response. We do not know whether the acquired offset response is triggered solely by the CS offset or by some combination of the CS offset and the passage of time from the CS onset. The majority of the units that acquired an offset response were US responsive before conditioning. The acquired offset response and the acquired US-timed response are concrete examples of how the spectrotemporal properties of an auditory cue can determine the neurophysiological expression of an associative modification.

\section{Aggregate analysis of acquired \\ CS responsiveness}

Units that were classified as gaining CS responsiveness after conditioning (Fig. 7, Table 2) are worth considering further. The CS might have elicited a small but statistically undetectable change in firing before conditioning. In this case, the conditioning-produced firing changes could likened to " $\alpha$ conditioning," an associative enhancement of a preexisting reflex or response. The most commonly reported firing changes in LA have been of this type (Quirk et al., 1995; Maren, 2000; Repa et al., 2001; Goosens et al., 2003; Hobin et al., 2003; Maren and Quirk, 2004). In search of subtle responses to the CS before conditioning, we examined the aggregate CS-elicited firing in all 31 units that acquired a phasic onset $(+)$ response after conditioning.

Figure 10 shows perievent histograms with mean $Z$ scores (from Eq. 1) in $10 \mathrm{~ms}$ bins. The plots are presented as a function of cue type and experimental stage, just before and just after the onset of the tone or USV. Two-tailed $t$ tests explored firing changes in bins corresponding to the time of the CS presentations. In these ad hoc $t$ tests, the $\alpha$ level was set at 0.05 per test (our usual Bonferroni's correction was not applied). This change greatly increased the statistical power to detect small changes in firing (at the expense of increasing the familywise $\alpha$ error rate). The Bonferroni's correction was only suspended in this one subsection of the results.

In the $22 \mathrm{kHz}$ tone group (Fig. 10A), before conditioning there was a hint in the aggregate plot of a small phasic $(+)$ onset
Table 2. Conditioning-produced changes in cue-elicited firing as a function of CS group

\begin{tabular}{|c|c|c|c|}
\hline Conditioning effect on unit firing & USV group & Tone group & Total \\
\hline \multicolumn{4}{|l|}{ Plastic } \\
\hline Became CS-responsive & 42 of $123(34 \%)$ & 24 of 77 (31\%) & 66 of $200(33 \%)$ \\
\hline Became CS-unresponsive & 17 of $123(14 \%)$ & 5 of $77(6 \%)$ & 22 of $200(11 \%)$ \\
\hline Changed firing pattern & 23 of $123(19 \%)$ & 33 of $77(43 \%)$ & 56 of $200(28 \%)$ \\
\hline $\begin{array}{l}\text { Maintained firing pattern and increased } \\
\text { firing frequency }\end{array}$ & 0 of $123(0 \%)$ & 0 of $77(0 \%)$ & 0 of $200(0 \%)$ \\
\hline $\begin{array}{l}\text { Maintained firing pattern and decreased } \\
\text { firing frequency }\end{array}$ & 1 of $123(1 \%)$ & 1 of $77(1 \%)$ & 2 of $200(1 \%)$ \\
\hline \multicolumn{4}{|l|}{ Nonplastic } \\
\hline $\begin{array}{l}\text { Maintained both firing pattern and firing } \\
\text { frequency }\end{array}$ & 7 of $123(6 \%)$ & 12 of $77(16 \%)$ & 19 of $200(10 \%)$ \\
\hline $\begin{array}{l}\text { CS-unresponsive during all stages of the } \\
\text { experiment }\end{array}$ & 33 of $123(27 \%)$ & 2 of $77(3 \%)$ & 35 of $200(18 \%)$ \\
\hline
\end{tabular}

Pre-exposure
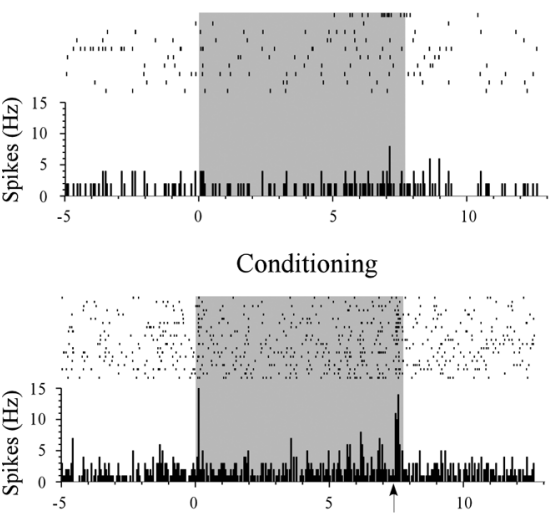

Testing

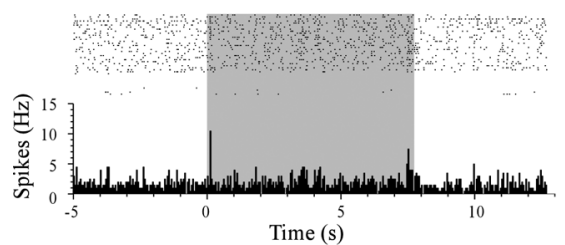

B

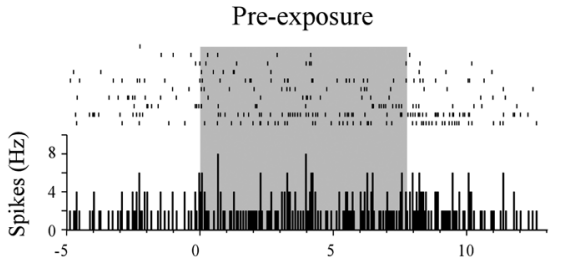

Conditioning

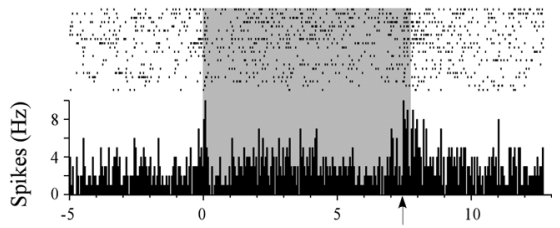

Testing

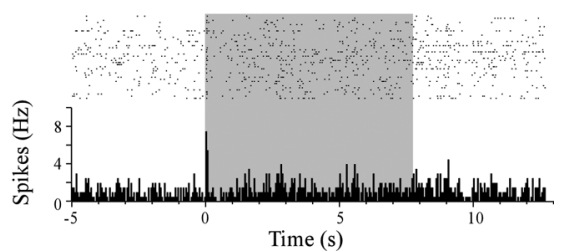

Figure 7. Acquired responsiveness to the two auditory stimuli. Time bins are $50 \mathrm{~ms}$. Results from the preexposure stage (10 , the conditioning stage ( 20 trials), and the testing stage ( 40 trials) are plotted on the same axes. $A$, Single-unit responses to uditory stimulus. During the conditioning phase, the unit acquired a phasic onset $(+)$ response. The arrow denotes the esponse. $\boldsymbol{B}$, Single-unit responses to the tone during the three stages of the experiment. During the preexposure period, the unit was unresponsive to the tone. During conditioning, the unit acquired a phasic onset $(+)$ response. The arrow denotes the time of the US, which also elicited firing. During the testing phase, the unit retained the phasic onset $(+)$ response.

response ( $n=14$ of 77 cells). However, the peak increase in firing (which occurred in the 30-40 ms time bin) was not statistically significant (Fig. $10 \mathrm{~A}$, open bars; mean $Z$ score, 1.44$)\left(t_{(13)}=1.81\right.$; $p>0.05)$. After conditioning, the firing level peaked in the $30-40$ ms time bin and was significantly elevated (Fig. $10 \mathrm{~A}$, filled bars; $Z$ score, 3.19) $\left(t_{(13)}=3.36 ; p<0.05\right)$. In an additional attempt to increase the statistical power, the results were reanalyzed and replotted (data not shown) using 50-ms-wide time bins. Recall that 50 -ms-wide time bins were used for the $t$ tests that determined single-unit responsiveness. In the tone group, the largest $Z$ score (which occurred in the time bin from 50 to $100 \mathrm{~ms}$ ) was 2.12 , which was not statistically significant $\left(t_{(13)}=2.11 ; p>\right.$ 0.05 ). After conditioning, the largest $Z$ score (which occurred in 
A

- - Unconditional Response (Pre-exposure)

O- Shock Response (Conditioning)

US-Timed Response (Testing)
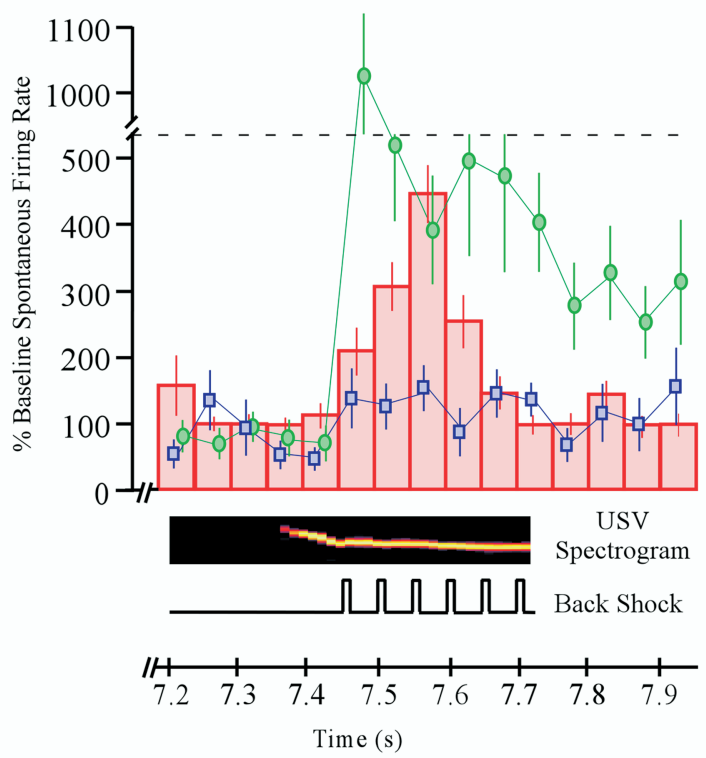

C

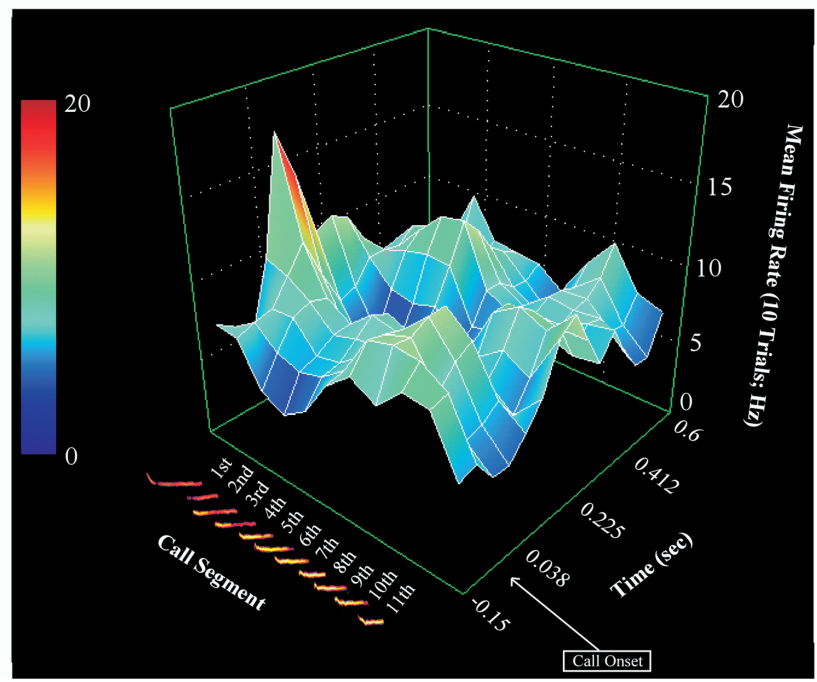

B

Pre-exposure
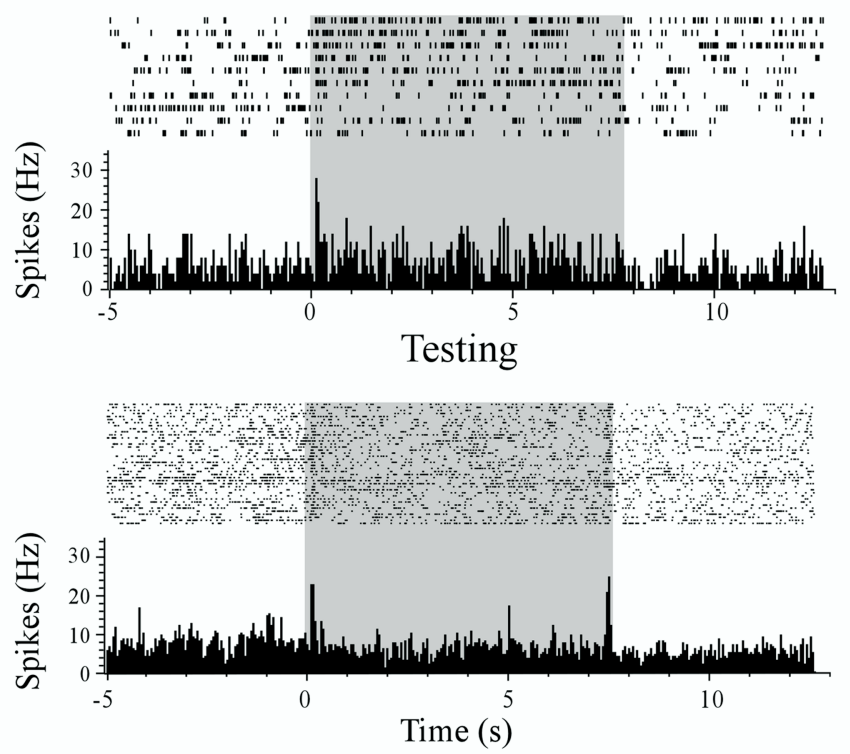

$\mathrm{D}$

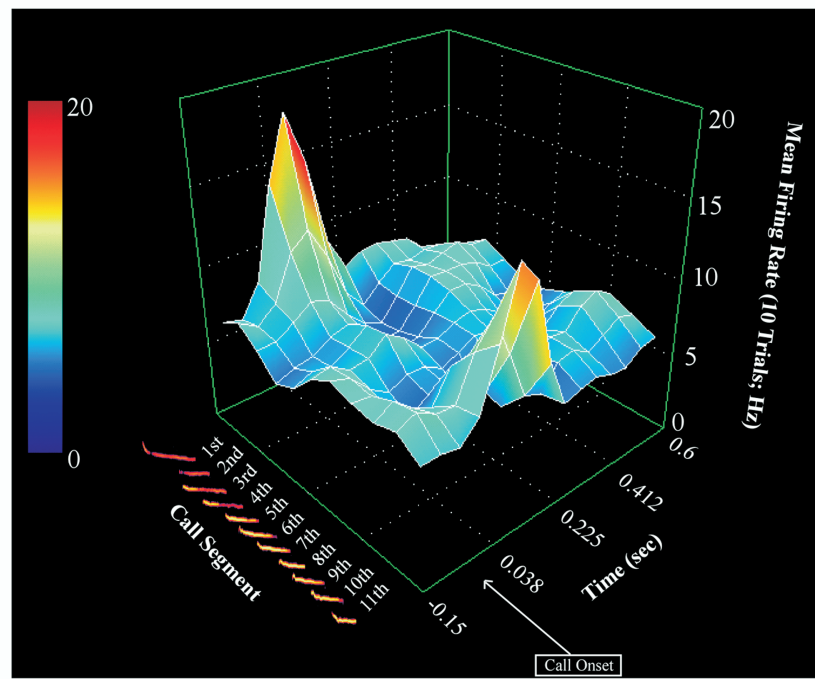

Figure 8. Acquisition of a US-timed firing pattern in response to the USV stimulus. The time bins are $50 \mathrm{~ms}$. A, Combined data from 14 units that acquired a US-timed firing pattern. The level of firing (expressed as a percentage of the baseline rate) is plotted across the last $512 \mathrm{~ms}$ of the USV and for the next $238 \mathrm{~ms}$ after the stimulus offset. Blue-shaded squares and red-shaded bars, respectively, show firing during the preexposure and testing periods. Green-shaded circles show responses to the US during conditioning. Error bars are \pm 1 SE. B, A perievent histogram and raster plot of a single unit that acquired a US-timed response. During the preexposure period, this unit only exhibited a phasic onset $(+)$ response to the first call. The shaded area denotes the presence of the USV. C, A three-dimensional contour plot showing firing in the same unit during the preexposure period. The firing rate only increased during the first call. $\boldsymbol{D}, \mathrm{A}$ three-dimensional contour plot showing firing in the same unit during the testing phase. The unit retained the original response during the first call and acquired a US-timed response during the last call. The responses to the first and last calls give the contour a distinctive saddle shape, which was only seen in response to the USV after conditioning.

the $0-50 \mathrm{~ms}$ time bin) was 5.57, which was significant $\left(t_{(13)}=\right.$ $6.29 ; p<0.05)$.

In the aggregate response from the USV group (Fig. $10 \mathrm{~B}$; based on $10 \mathrm{~ms}$ time bins), there was a statistically insignificant response before conditioning (Fig. $10 \mathrm{~B}$, open bars; peak bin, $80-90$ ms latency; $Z$ score, 1.29$)\left(t_{(16)}=1.78 ; p>0.05\right)$. After conditioning, the level of firing in this time interval was significantly elevated (Fig. $10 \mathrm{~B}$, filled bars; peak bin, 60-70 ms latency; $Z$ score, 2.42) $\left(t_{(16)}=2.60 ; p<0.05\right)$. To increase the statistical power, these data were reanalyzed using 50 ms bins. Before con- ditioning, the largest $Z$ score (in the time bin from 50 to $100 \mathrm{~ms}$ ) was 1.78 , which was statistically insignificant $\left(t_{(16)}=1.92 ; p>\right.$ 0.05 ). After conditioning, the largest $Z$ score (also in the 50-100 ms time bin) was 4.61, which was significant $\left(t_{(16)}=4.27\right.$; $p<$ $0.05)$. The pattern of statistical significance turned out to be the same when the usual Bonferroni's correction was applied.

\section{CS-specific differences in firing latencies}

The plots in Figure 10 illustrate cue-specific difference in the firing latency after conditioning. Latency differences were further 
A
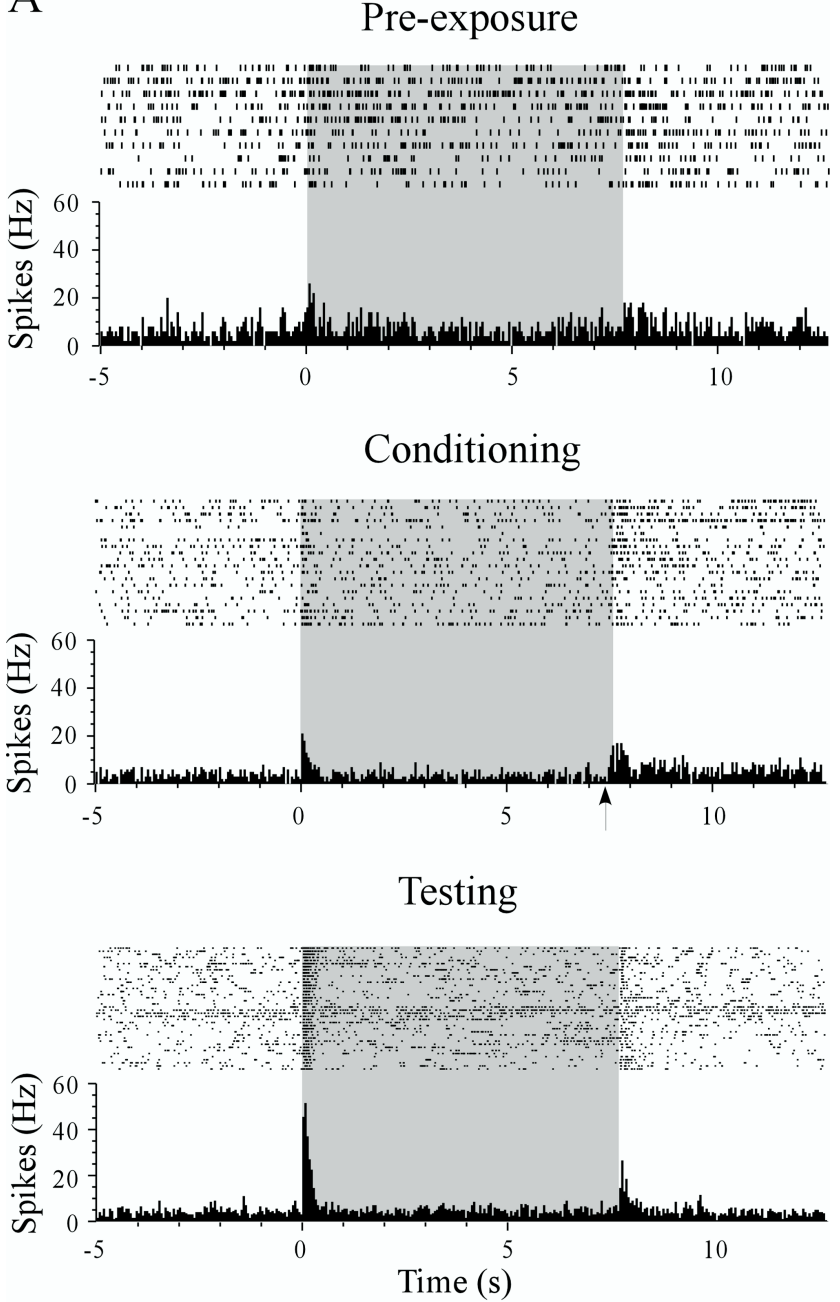

B

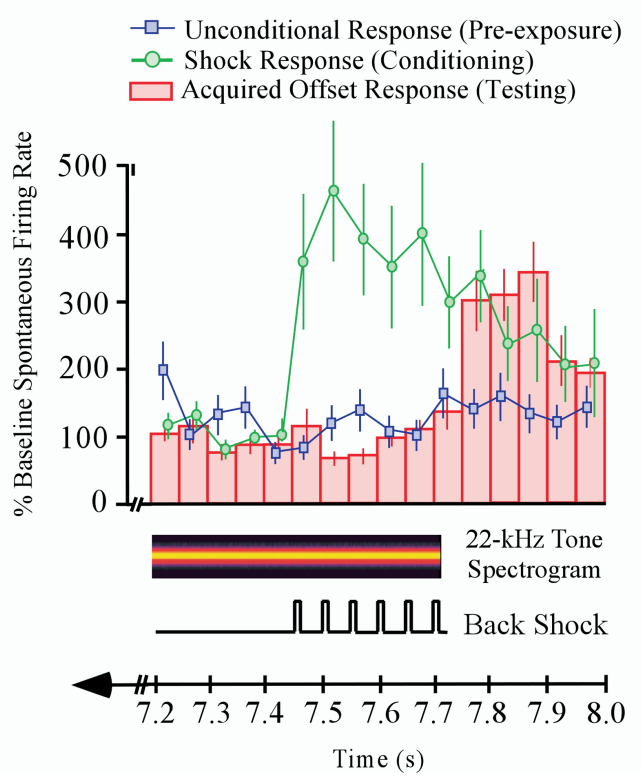

Figure 9. Acquired phasic onset $(+)$ and phasic offset $(+)$ responses to the $22 \mathrm{kHz}$ tone. The time bins are $50 \mathrm{~ms}$. $\boldsymbol{A}$, Histograms and raster plots are shown for an example cell during the preexposure (top), conditioning (middle), and testing (bottom) phases of the experiment. The shaded area denotes the presence of the tone, and the arrow indicates the time of shock. Before conditioning, this unit did not exhibit any statistically significant responses to the tone. During examined in the 31 units that acquired a phasic onset $(+)$ response after conditioning. Significant changes in mean $Z$ score latencies (from preexposure to testing) were evaluated using twotailed $t$ tests for dependent samples. In the tone-conditioned group, the earliest firing changes occurred in the interval between 20 and $30 \mathrm{~ms}$ after the CS onset $\left(t_{(13)}=3.58 ; p<0.05\right)$. In the USV-conditioned group, the earliest change in firing occurred in the interval between 50 and $60 \mathrm{~ms}$ after the CS onset $\left(t_{(16)}=2.67\right.$; $p<0.05)$. A different $t$ test for independent samples compared the latencies between the tone and USV groups after conditioning. The difference between the mean firing latencies in the tone $(27.9 \pm 2.8 \mathrm{~ms})$ and USV $(57.1 \pm 6.2)$ groups was significant $\left(t_{(29)}=3.98 ; p<0.05\right)$.

The $\sim 30 \mathrm{~ms}$ difference in firing latencies to the two cues (Fig. 10) raises the question of whether conditioning caused the difference. The answer obviously cannot be obtained from the sample of 31 cells that are included in Figure 10, because these units were CS unresponsive before conditioning. One approach we used to address this question was based on a sample of 52 cells that were classified as giving a simple phasic onset $(+)$ response before conditioning (during the CS preexposure period). The responses were simple in that the cues elicited no other response patterns (Table 1). Before conditioning, there was no significant difference between the mean firing latency in the USV $(53.3 \pm 1.8 \mathrm{~ms})$ and the tone $(56.2 \pm 5.0 \mathrm{~ms})$ groups $\left(t_{(50)}=-0.59 ; p>0.05\right)$. A previous neurophysiological study of naive rats (Allen et al., 2007a) found similar firing latencies to the USV $(59.3 \pm 6.3 \mathrm{~ms})$ and the tone $(55.7 \pm 6.6 \mathrm{~ms}$ ) stimuli (unpublished analysis of data reported by Allen et al., 2007a). The mean firing latencies to these two cues differed by $\sim 30 \mathrm{~ms}$ after conditioning, but they were within a few milliseconds of each other before conditioning.

A parallel approach we used to address the same question was based on a sample of 57 cells that maintained a phasic onset $(+)$ firing component before and after conditioning. This sample included units that may have produced more complex firing patterns [ such as a phasic onset $(+) /$ tonic $(-)$ response]. Thirty-one of the units that met the criterion for inclusion were among the previously described 52 units that produced a simple phasic onset $(+)$ response. In the tone group, 36 units exhibited a phasic onset $(+)$ response component before and after conditioning. A $t$ test for dependent samples evaluated changes in mean firing latencies associated with conditioning. The firing onset latency during testing $(41.1 \pm 2.6)$ was significantly shorter than the latency during the preexposure phase $(49.2 \pm 3.7)\left(t_{(35)}=-2.08 ; p<\right.$ $0.05)$. In the USV group, 21 cells exhibited a phasic onset $(+)$ response component both before and after conditioning. Among these cells, the onset latency during testing $(56.2 \pm 4.3)$ was not significantly different from the latency during the preexposure phase $(53.3 \pm 2.0)\left(t_{(20)}=0.77 ; p>0.05\right)$.

In summary, there was a significant firing latency difference between the two cues after conditioning, no significant difference in firing latency difference between the two cues before condi-

$\leftarrow$

conditioning, this unit did not exhibit any statistically significant responses to the tone. During conditioning, the unit has acquired a phasic onset $(+)$ response. At this point, it is uncertain whether the response at the end of the cue is an acquired phasic offset $(+)$ response or a response to the US. During testing, this unit demonstrated a phasic onset $(+)$ response as well as a phasic offset $(+)$ response. $\boldsymbol{B}$, Combined data from the 23 cells that acquired a phasic offset $(+)$ firing pattern. The level of firing (expressed as a percentage of the baseline rate) is plotted across the last $500 \mathrm{~ms}$ of the tone and the next $288 \mathrm{~ms}$ after the tone offset. Blue-shaded squares and red-shaded bars, respectively, show firing during the preexposure and testing periods. Green-shaded circles show responses to the US during conditioning. Error bars are $\pm 1 \mathrm{SE}$. 
A

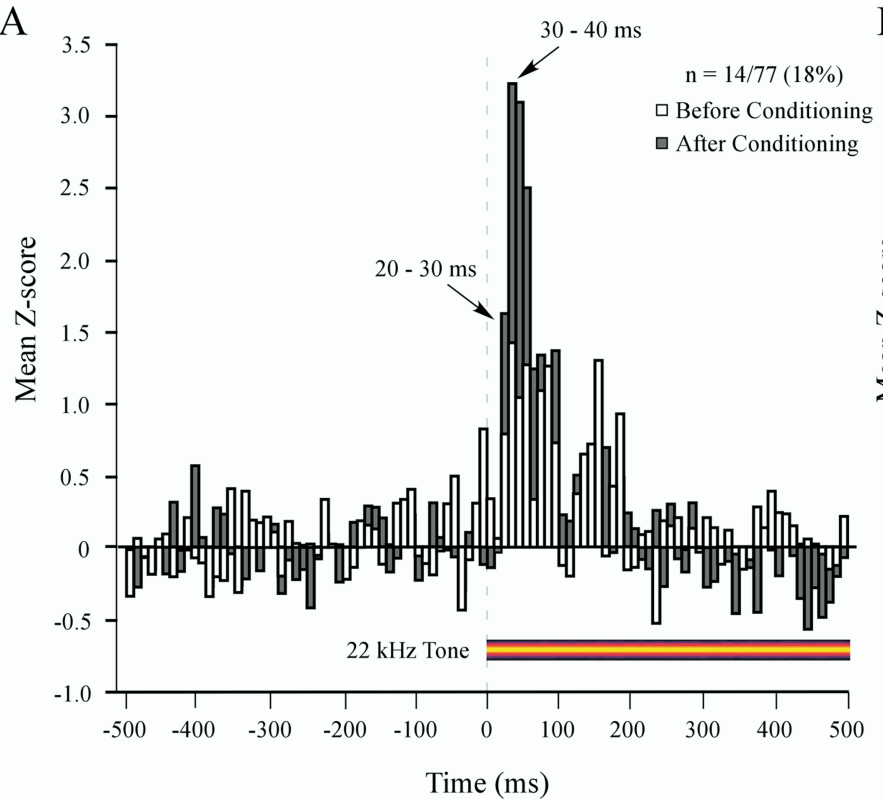

B

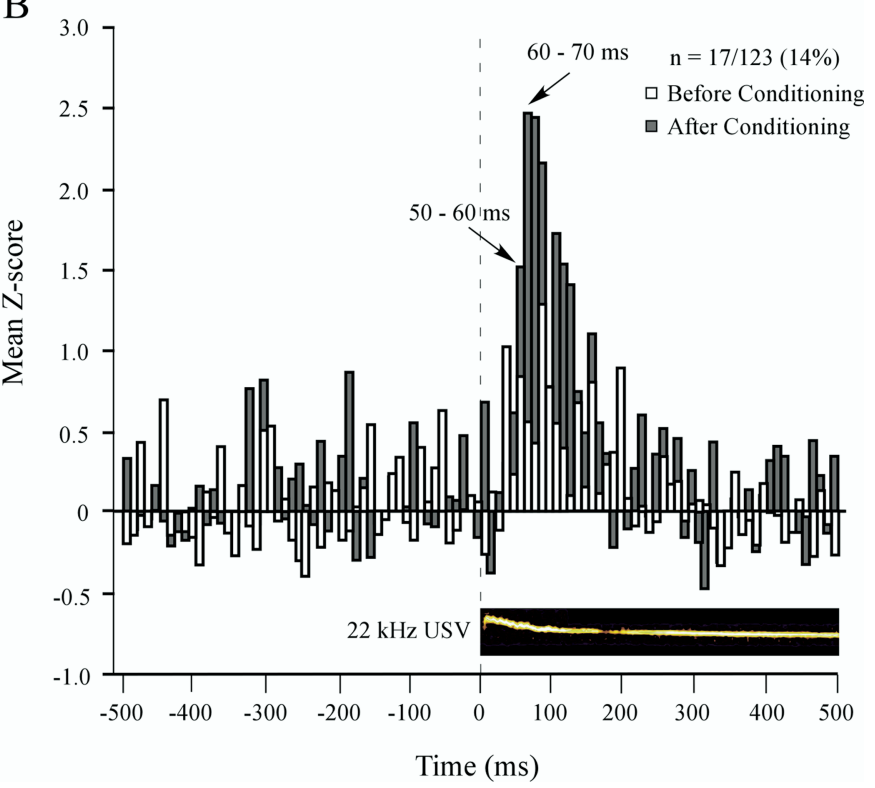

Figure 10. Latencies of acquired phasic onset $(+)$ firing patterns to the two auditory cues. Firing rates for each unit and each time bin were transformed to $Z$ scores (from Eq. 1 ) and then averaged. The $Z$ scores compared the firing rate in each $10 \mathrm{~ms}$ time bin with the firing rate during the $5 \mathrm{~s}$ baseline period just before the stimulus onset. Only the first $250 \mathrm{~ms}$ of the auditory stimulus presentation is shown. Open and filled bars, respectively, show the time course of firing rate during the preexposure and testing periods. $A$, The tone caused no statistically significant firing changes during the preexposure period. During the testing period, the earliest time bin to show a statistically significant increase in firing rate occurred in the interval from 20 to $30 \mathrm{~ms}$. The maximum firing rate occurred in the interval from 30 to $40 \mathrm{~ms}$. B. The USV caused no statistically significant firing changes during the preexposure period. During the testing period, the earliest time bin to show a statistically significant increase in firing rate occurred in the interval from 50 to $60 \mathrm{~ms}$. The maximum firing rate occurred in the interval from 60 to $70 \mathrm{~ms}$.

tioning, a significant firing latency decrease associated with conditioning to the tone, and no significant firing latency change associated with conditioning to the USV. The overall pattern of results indicates that fear conditioning selectively decreased the firing latency to the tone. We suggest a simple neurophysiological mechanism that might account for this pattern of results in Discussion below.

\section{Freezing behavior during testing}

Because of recording errors, freezing behavior could only be analyzed in 27 of 28 subjects. In three animals, only the first $7 \mathrm{~min}$ of testing (of $16 \mathrm{~min}$ ) could be scored. Physiological data were included in the analysis from all 28 subjects. Fifteen subjects were conditioned to the USV cue, and 13 subjects were conditioned to the tone cue. The USV- and tone-conditioned groups showed comparable levels of freezing during testing (Fig. 11). A two-way ANOVA revealed no significant difference between the two cue groups $(p>0.05)$ and no significant time bin $\times$ group interaction $(p>0.05)$.

Data from both groups were therefore combined for additional analysis. During the first minute of cue presentation, the average level of freezing $(86 \%)$ was significantly elevated over the baseline level $(28 \%)\left(t_{(26)}=8.96 ; p<0.05\right)$. Overall, the back shock served as an effective US, causing a relatively high level of cue-elicited freezing (Fig. 11) $(d=2.2)$. The overall level of freezing decreased across time within the testing/extinction session. Pooling data from both groups, the percentage freezing decreased from its highest level of $97 \%$ in the third time bin to $66 \%$ in the 12th time bin. Freezing levels were negatively correlated with time across the first to the 16th time bins (Pearson's $r=-0.24$; $p<0.05)$ but remained elevated above the baseline values during the last minute of cue testing $\left(t_{(23)}=5.35 ; p<0.05\right)$.

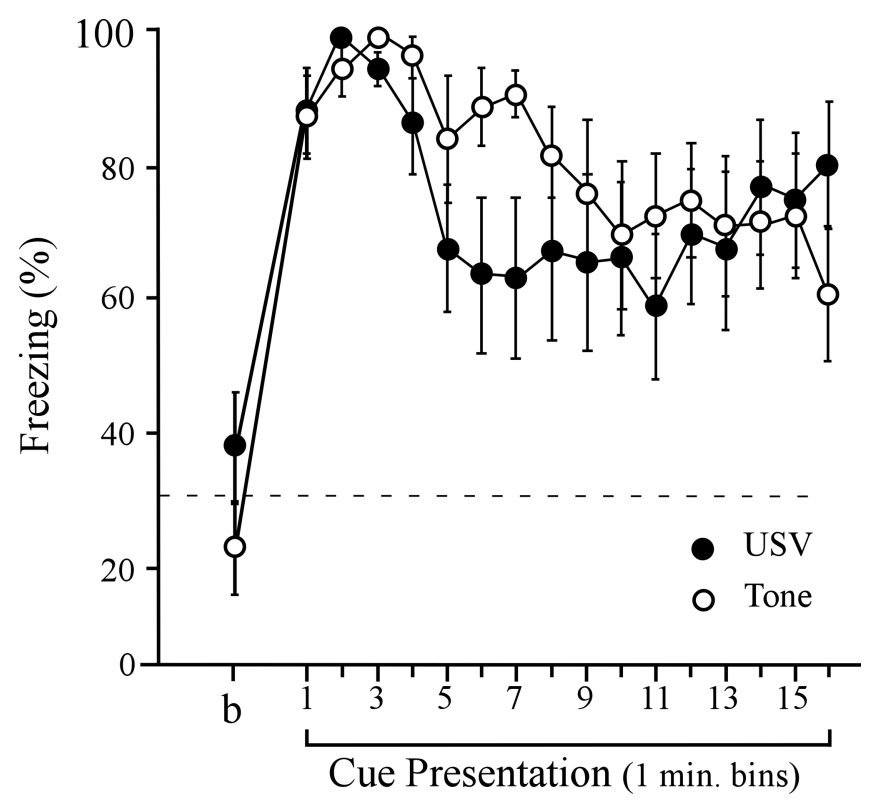

Figure 11. Similar levels of freezing elicited by the tone and USV cues during the testing phase of the experiment. Conditioning consisted of $20 \mathrm{CS}-U \mathrm{~S}$ pairings. During testing, freezing to the conditioning context was scored during a 2 min baseline period (labeled b) just before the first CS onset. Animals then received 40 CS-alone (extinction) trials during the next 16 min. Freezing was scored in 1 min time bins. The dashed line is the mean baseline freezing level of the combined groups. Error bars are $\pm 1 \mathrm{SE}$. During first few CS-alone presentations, the peak freezing levels were so high that a ceiling effect could have obscured group differences.

\section{Discussion}

Overall summary of neurophysiological results

Both the tone and the USV cues were effective in supporting conditional changes in CS-elicited firing (Table 2, Figs. 7-10), 
which occurred in a large proportion of PR units $(73 \% ; 145$ of $200)$. These widespread changes may partly reflect the considerable convergence of auditory and somatosensory information in PR (Table 1). This extensive convergence furnishes numerous opportunities for associative synaptic modifications to occur (Brown et al., 1990, 2004, 2007). The expanded analysis performed here, which examined types of firing changes (Table 2) that are not usually reported in neurophysiological studies of auditory fear conditioning, also increased the percentage of plastic units. Importantly, one-third of the cells that were initially unresponsive to the CS became responsive after fear conditioning (Table 2, Fig. 7). Conditioning-produced transitions from CS unresponsive to CS responsive are theoretically predicted to occur. Note that conditioning also caused some CS-responsive neurons to become CS unresponsive (Table 2).

After conditioning, single-unit responses to the tone and USV cues differed in two respects. First, there were cue-specific patterns of acquired firing (Figs. 8, 9). During the testing phase of the experiment, the USV (but not the tone) sometimes elicited a US-timed response, whereas the tone (but not the USV) sometimes elicited an acquired phasic offset $(+)$ response. Second, conditioning to the tone (but not the USV) shortened the firing latency. Among units that acquired a phasic onset $(+)$ response, the mean firing latency to the tone was $\sim 30 \mathrm{~ms}$ shorter than the mean firing latency to the USV (Fig. 10).

\section{Implications of cue-specific differences in firing latencies}

Studies of the amygdala have productively used CS-elicited firing latencies to make inferences about the critical circuitry involved in fear conditioning (Quirk et al., 1995; Repa et al., 2001). The rationale was that short-latency responses ( $\leq 20 \mathrm{~ms}$ ) elicited by tones are most likely to be driven by subcortical projections from the auditory thalamus. In the present study, the mean latency of acquired firing to the tone onset was considerably shorter (by $\sim 30 \mathrm{~ms}$ ) than the mean latency of acquired firing to the USV onset. The latency to the first significant firing increase to the tone (20-30 ms time bin) was slightly longer than the shortest latencies in the lateral nucleus of the amygdala (10-20 ms time bin) (Quirk et al., 1995, 1997). The firing latency to the USV (50-60 ms time bin) was similar to the firing latency to tones in auditory cortex (Quirk et al., 1997; Armony et al., 1998).

The overall analysis showed that fear conditioning caused the firing latency to shorten in the tone group but not in the USV group. The pattern of results is consistent with the possibility that, after conditioning, the subcortical CS projections to PR gained some control of firing to the onset of the tone but not the USV. Why does the latency decrease only occur when the tone serves as the CS? One obvious possibility is that continuous tones are most favorable for inducing neuronal plasticity in the subcortical projections to $\mathrm{PR}$, whereas certain time-varying auditory stimuli are more effective in inducing plasticity in the cortical projections to PR. The results support the hypothesis that conditional responses to simple and complex auditory stimuli are supported, respectively, by subcortical and cortical CS pathways (LeDoux, 2000; Yaniv et al., 2001; Yaniv et al., 2004; Lindquist et al., 2004; Padlubnaya et al., 2006a).

When the CS is a tone, subcortical auditory pathways may normally cause modifications in both the amygdala and PR. Alternatively, the short-latency modifications in PR could be secondary consequences of primary changes within the amygdala. In either case, there is obviously no contradiction between the fact that PR is not necessary for conditioning to tone cues and the fact that tone conditioning causes firing changes in PR neurons. Anal- ogous findings are well known in the classical studies of delay eyeblink conditioning and hippocampal function (Berger and Thompson, 1976; McCormick et al., 1982; McCormick and Thompson, 1984).

\section{ISI encoding as revealed in behavior and neurophysiology}

Rats are known to encode the relatively long ISIs that are commonly used in fear-conditioning experiments. This fact was demonstrated by measuring either of two "fast CRs": facilitation of the R1 component of the eyeblink reflex (Lindquist and Brown, 2004) or potentiation of the acoustic startle response (Davis et al., 1989; Burman and Gewirtz, 2004). The amplitude of these CRs is greatest when they are tested at the training ISI (Davis et al., 1989; Burman and Gewirtz, 2004; Lindquist and Brown, 2004). Based on these results, it follows that there must be neurons in the fear conditioning circuitry whose firing can encode the conditioning ISI. Interestingly, PR has been hypothesized to play a critical role in ISI encoding in fear conditioning (Fendt and Fanselow, 1999; Domjan, 2006; Padlubnaya et al., 2006b).

This hypothesis was partly based on a simple model (Faulkner et al., 1997; Faulkner and Brown, 1999; Tieu et al., 1999) of fear conditioning in which timing emerges through chains of socalled "late-spiking" PR neurons (Faulkner and Brown, 1999; McGann et al., 2001; Moyer et al., 2002; Moyer and Brown, 2007). These chains formed a suite of what might be termed "analog tap delay lines." Circuit simulations demonstrated that suites of these delay lines can combine with Hebbian synaptic modifications (Brown et al., 1990, 2004, 2007) to furnish reasonably accurate ISI encoding, even in the presence of considerable synaptic noise (Tieu et al., 1999; McGann and Brown, 2000; Padlubnaya et al., 2006b). The discovery of US-timed firing (Fig. 8) lends support to the hypothesis that PR participates in ISI encoding.

The US-timed firing pattern, which was sometimes but only elicited by the USV, was restricted to the $260 \mathrm{~ms}$ interval that previously contained the US (Fig. 8). To appreciate the precision and range of this temporal encoding will require studies of several different ISIs. Additional interpretation of US-timed firing will depend on the effects of varying the CS properties during the conditioning or testing periods. For example, if the 11 th call were eliminated during testing, would the first 10 calls elicit US-timed firing? Such a "temporally reconstructive" effect would imply that the entire call sequence is being treated as an entity or "auditory object" (Kubvoy and Van Valkenburg, 2001; Tian et al., 2001; Gentner and Margoliash, 2003; Griffiths and Warren, 2004) during recall. At the other extreme, US-timed firing might be exclusively controlled by the 11th call. In this case, presentation of the first 10 calls during testing should not elicit US-timed firing, whereas presentation of the 11 th call by itself should elicit the complete response. It remains to be determined whether a single-call cue can even support delay fear conditioning.

\section{Effect of sensitization or context conditioning on cue-elicited firing}

Changes in cue-elicited firing could theoretically reflect context conditioning or a nonspecific sensitization rather than a consequence of explicit pairings of the CS with the US (Weinberger, 2004; Maren, 2005; Thompson, 2005). We addressed this issue using both within- and between-subjects analyses. A subset of animals $(n=21)$ received explicitly unpaired CS and US presentations during the preexposure period and paired presentations during the conditioning period. Sensitization or context-conditioning effects were implicitly controlled by 
comparing single-unit firing in unpaired and paired phases of the experiment. A within-subjects analysis was motivated by the known heterogeneity of PR neurons (Faulkner and Brown, 1999; Allen et al., 2007a; Furtak et al., 2007b; Moyer and Brown, 2007). The remaining animals $(n=7)$ received CSalone presentations during preexposure period and enabled a between-subjects statistical evaluation of possible US effects. There were no significant differences between the two preexposure groups in terms of spontaneous firing rates, the overall level of single-unit responsiveness, or the range of cue-elicited firing patterns.

Most importantly, US-timed firing (Fig. 8) cannot be explained in terms of context conditioning or sensitization. First, this firing pattern was only seen after explicit CS-US pairings. Second, the firing change was limited to the small interval within which the US had previously occurred (Fig. $8 A$ ). In fact, the peak firing rate occurred within $50 \mathrm{~ms}$ of the midpoint of the $260 \mathrm{~ms}$ interval that previously contained the US (Fig. 8 A). Sensitization or context conditioning cannot explain a sudden increase in firing in such a small time interval. US-timed firing is perhaps the strongest possible evidence of plasticity that specifically depends on CS-US pairings. Differential conditioning procedures should prove useful in further evaluating sensitization or context conditioning effects (Hobin et al., 2003; Weinberger, 2004). A theoretical limitation is that differential conditioning changes the nature of the learning task and increases its complexity. A practical problem is that stimulus generalization between cue pairs can be quite asymmetrical (Bang et al., 2006).

Origin of conditioning-produced changes in CS-elicited firing Auditory fear conditioning is known to cause changes in CSelicited firing in the amygdala and auditory cortex (for review, see Maren and Quirk, 2004; Weinberger, 2004). Because the amygdala and auditory cortex both project to PR, the firing changes observed in the present study could have originated in one of these other structures. Some of the types of plasticity documented here have not been described in the amygdala or auditory cortex. However, direct comparisons with these other structures cannot be made because of differences in procedures and analysis. The obvious next step is to perform simultaneous recordings, using the procedures described here, from the amygdala, PR, and auditory cortex. The origins of plasticity can be further evaluated by combining these recordings with reversible inactivations of amygdala, PR, or auditory cortex (Allen et al., 2007b).

\section{Perspectives on continuous tones and USVs as conditional stimuli \\ Behavioral responses to tones and USVS}

Continuous tones and auditory social signals are respective exemplars of arbitrary and ecological stimuli (Domjan et al., 2004). Behavioral studies have demonstrated that arbitrary and ethological stimuli can differ with respect to several pavlovian conditioning phenomena, including extinction, second-order conditioning, blocking, and the effects of increasing the conditioning ISI (for review, see Domjan et al., 2004). Endres et al. (2007) recently reported that fear conditioning to a $22 \mathrm{kHz}$ USV is more resistant to extinction than fear conditioning to a $22 \mathrm{kHz}$ tone. They also found that, before conditioning, tones and USV were equally "neutral" in terms of the elicitation of freezing behavior. Our studies also found no differences in unconditional freezing elicited by USVs and tones (Tankhiwale et al., 2007). These findings suggest that defensive responses to $22 \mathrm{kHz}$ USV s are not innate.
Neurophysiological responses to tones and USVs

The results show that, before conditioning, tones and USVs elicit firing in approximately the same proportion of PR units, although there are some interesting differences in the elicited firing patterns (Table 1) (Allen et al., 2007a). Tone-elicited firing was not unexpected. After all, tones elicit firing in the auditory thalamus and the auditory cortex (Bordi and LeDoux, 1994; Rutkowski et al., 2003), two structures that furnish most of the auditory input to PR (Burwell and Amaral, 1998; Linke, 1999; Doron and LeDoux, 2000; Kimura et al., 2003; Furtak et al., 2007a). At the outset of our studies (Allen et al., 2007a), there was no basis for predicting the prevalence of USV-elicited firing in PR before or after conditioning. Neurophysiological responses to auditory social signals had been reported in monkeys (Rauschecker and Tian, 2000; Romanski et al., 2005) but not rats.

Tones and USVs were equally effective in supporting singleunit plasticity in PR. However, after conditioning, the firing latencies were considerably shorter when the CS was a tone. A reasonable explanation is that acquired firing changes elicited by the tone onset are supported by the subcortical CS pathways to PR. The latter might reflect direct projections from the auditory thalamus to PR (Doron and LeDoux, 2000; Furtak et al., 2007a) or indirect projections from auditory thalamus to the amygdala and from there to PR (Shi and Cassell, 1997, 1999; Pikkararinen and Pitkanen, 2001; Furtak et al., 2007a). Either way, the results suggest that subcortical projections to PR can gain control of firing to the onset of a tone but not to the onset of a USV. Thus, different CS pathways support responses to tones and USVs after conditioning.

\section{Final conclusions and theoretical implications}

Six neurophysiological findings were most significant in terms of understanding conditioning-produced neuronal plasticity in PR. First, before conditioning, nearly half of the sampled neurons were responsive to both the US and at least one of the two auditory CSs. Each of these convergence sites is potentially subject to associative synaptic modifications during fear conditioning (Brown et al., 1990, 2004, 2007). One would therefore expect both cues to support widespread plasticity. Second, in agreement with this expectation, conditioning to both cues did in fact cause widespread changes in elicited firing, showing that PR is normally engaged regardless of whether the cue is a tone or a USV.

Third, many CS-unresponsive PR neurons became CS responsive after conditioning. These transitions from unresponsive to responsive are theoretically predicted to occur within the essential memory circuits. Fourth, some PR neurons acquired UStimed firing in response to the USV but not the tone. This discovery is consistent with previous suggestions (Fanselow and LeDoux, 1999; Domjan, 2006; Padlubnaya et al., 2006b) that PR plays a role in ISI encoding. Fifth, before conditioning, the firing latencies to the tone $(53 \pm 2 \mathrm{~ms})$ and the USV $(56 \pm 5 \mathrm{~ms})$ were comparable (Allen et al., 2007). These relatively long firing latencies suggest that, before conditioning, cue-elicited firing was mediated by cortical rather than subcortical pathways to PR.

Sixth, conditioning to the tone caused the firing latency to decrease substantially (by $30 \mathrm{~ms}$ ), whereas conditioning to the USV had no effect on the firing latency. Based on the firing latencies before and after conditioning, we suggest that subcortical CS pathways gained control of firing to the onset of the tone but not the USV. The same experiments need to be conducted on singleunit responses in the amygdala. If conditional unit responses to USVs and tones similarly occur at long and short latencies, respectively, this could help explain why PR lesions impair condi- 
tioning to USVs but not tones. The overall findings from the present study support the hypothesis (Lindquist et al., 2004; Padlubnaya et al., 2006a) that the spectrotemporal properties of a cue can determine critical aspects of the fear-conditioning circuitry (Yaniv et al., 2001, 2004).

\section{References}

Allen TA, Furtak SC, Brown TH (2007a) Single-unit responses to $22 \mathrm{kHz}$ ultrasonic vocalizations in rat perirhinal cortex. Behav Brain Res 182:327-336.

Allen TA, Narayanan NS, Kholodar-Smith DB, Zhao YJ, Laubach M, Brown TH (2007b) Imaging the spread of reversible inactivation using a fluorescent $\mathrm{GABA}_{\mathrm{A}}$ agonist. Soc Neurosci Abstr 33:533.29.

Anderson JW (1954) The production of ultrasonic sounds by laboratory rats and other mammals. Science 119:808-809.

Armony JL, Quirk GJ, LeDoux JE (1998) Differential effects of amygdala lesions on early and late plastic components of auditory cortex spike trains during fear conditioning. J Neurosci 18:2592-2601.

Bang S, Allen TA, Jones LK, Boguszewski P, Brown TH (2006) Asymmetrical generalization gradients toward social alarm calls in rats given differential fear conditioning. Soc Neurosci Abstr 32:67.15.

Barfield RJ, Geyer LA (1972) Sexual behavior: ultrasonic postejaculatory song of the male rat. Science 176:1349-1350.

Berger TW, Thompson RF (1976) Neuronal substrate of classical conditioning in the hippocampus. Science 192:483-485.

Blanchard RJ, Blanchard DC (1969) Crouching as an index of fear. J Comp Physiol Psychol 67:370-375.

Blanchard RJ, Blanchard DC, Agullana R, Weiss SM (1991) Twenty-two $\mathrm{kHz}$ alarm cries to presentation of a predator, by laboratory rats living in visible burrow systems. Physiol Behav 50:967-972.

Boatman JA, Kim JJ (2006) A thalamo-cortico-amygdala pathway mediates auditory fear conditioning in the intact brain. Eur J Neurosci 24:894-900.

Bordi F, LeDoux JE (1994) Response properties of single units in areas of rat auditory thalamus that project to the amygdala. I. Acoustic discharge patterns and frequency receptive fields. Exp Brain Res 98:261-274.

Brown TH, Kairiss EW, Keenan CL (1990) Hebbian synapses: biophysical mechanisms and algorithms. Annu Rev Neurosci 13:475-511.

Brown TH, Byrne JH, Labar K, LeDoux J, Lindquist DH, Thompson RF, Teyler TJ (2004) Learning and memory: basic mechanisms. In: From molecules to networks: an introduction to cellular and molecular neuroscience (Byrne JH, Roberts JL, eds), pp 499-574. San Diego: Academic.

Brown TH, Zhao Y, Leung V (2007) Hebbian synapses. In: Encyclopedia of neuroscience, Ed 4 (Adelman G, Smith BH, eds). New York: Elsevier Science.

Brudzynski SM (2005) Principles of rat communication: quantitative parameters of ultrasonic calls in rats. Behav Genet 35:85-92.

Brudzynski SM (2007) Ultrasonic calls of rats as indicator variables of negative or positive states. Acetylcholine-dopamine interaction and acoustic coding. Behav Brain Res 182:261-273.

Brudzynski SM, Holland G (2005) Acoustic characteristics of air puffinduced $22-\mathrm{kHz}$ alarm calls in direct recordings. Neurosci Biobehav Rev 29:1169-1180.

Brudzynski SM, Bihari F, Ociepa D, Fu XW (1993) Analysis of 22 kHz ultrasonic vocalization in laboratory rats: long and short calls. Physiol Behav 54:215-221.

Bucci DJ, Phillips RG, Burwell RD (2000) Contributions of postrhinal and perirhinal cortex to contextual information processing. Behav Neurosci 114:882-894.

Bucci DJ, Saddoris MP, Burwell RD (2002) Contextual fear discrimination is impaired by damage to the postrhinal or perirhinal cortex. Behav Neurosci 116:479-488.

Bures J, Burresova O (1970) Plasticity in single neurons and neural populations. In: Short-term changes in neuronal activity and behavioral (Horn G, Hinde RA, eds), pp 363-403. Cambridge, UK: Cambridge UP.

Burman MA, Gewirtz JC (2004) Timing of fear expression in trace and delay conditioning measured by fear-potentiated startle in rats. Learn Mem 11:205-212.

Burwell RD (2000) The parahippocampal region: corticocortical connectivity. Ann NY Acad Sci 911:25-42.

Burwell RD (2001) Borders and cytoarchitecture of the perirhinal and postrhinal cortices in the rat. J Comp Neurol 437:17-41.
Burwell RD, Amaral DG (1998) Cortical afferents of the perirhinal, postrhinal, and entorhinal cortices of the rat. J Comp Neurol 398:179-205.

Burwell RD, Witter MP, Amaral DG (1995) Perirhinal and postrhinal cortices of the rat: a review of the neuroanatomical literature and comparison with findings from the monkey brain. Hippocampus 5:390-408.

Cahill L, Weinberger NM, Roozendaal B, McGaugh JL (1999) Is the amygdala a locus of "conditioned fear"? Some questions and caveats. Neuron 23:227-228.

Chimoto S, Kitama T, Qin L, Sakayori S, Sato Y (2002) Tonal response patterns of primary auditory cortex neurons in alert cats. Brain Res 934:34-42.

Choi JS, Brown TH (2003) Central amygdala lesions block ultrasonic vocalization and freezing as conditional but not unconditional responses. J Neurosci 23:8713-8721.

Corodimas KP, LeDoux JE (1995) Disruptive effects of posttraining perirhinal cortex lesions on conditioned fear: contributions of contextual cues. Behav Neurosci 109:613-619.

Davis M, Schlesinger LS, Sorenson CA (1989) Temporal specificity of fear conditioning: effects of different conditioned stimulus-unconditioned stimulus intervals on the fear-potentiated startle effect. J Exp Psychol Anim Behav Process 15:295-310.

Domjan M (2006) The principles of learning and behavior: active learning edition, Ed 5. Belmont, CA: Thomson-Wadsworth.

Domjan M, Cusato B, Krause M (2004) Learning with arbitrary versus ecological conditioned stimuli: evidence from sexual conditioning. Psychol Bull Rev 11:232-246.

Doron NN, LeDoux JE (2000) Cells in the posterior thalamus project to both amygdala and temporal cortex: a quantitative retrograde doublelabeling study in the rat. J Comp Neurol 425:257-274.

Endres T, Widmann, K, Fendt M (2007) Are rats predisposed to learn 22 $\mathrm{kHz}$ calls as danger-predicting signals? Behav Brain Res, in press.

Fanselow MS, LeDoux JE (1999) Why we think plasticity underlying Pavlovian fear conditioning occurs in the basolateral amygdala. Neuron 23:229-232.

Fanselow MS, Poulos AM (2005) The neuroscience of mammalian associative learning. Annu Rev Psychol 56:207-234.

Faulkner B, Brown TH (1999) Morphology and physiology of neurons in the rat perirhinal-lateral amygdala area. J Comp Neurol 411:613-642.

Faulkner B, Tieu KH, Brown TH (1997) Mechanism for temporal encoding in fear conditioning. In: Computational neuroscience (Bower, JM ed), pp 641-645. New York: Plenum.

Fendt M, Fanselow MS (1999) The neuroanatomical and neurochemical basis of conditioned fear. Neurosci Biobehav Rev 23:743-760.

Furtak SC, Wei SM, Agster KL, Burwell RD (2007a) Functional neuroanatomy of the parahippocampal region in the rat: the perirhinal and postrhinal cortices. Hippocampus 17:709-722.

Furtak SC, Moyer JR, Brown TH (2007b) Morphology and ontogeny of rat perirhinal cortical neurons. J Comp Neurol 505:493-510.

Gale GD, Anagnostaras SG, Godsil BP, Mitchell S, Nozawa T, Sage JR, Wiltgen B, Fanselow MS (2004) Role of the basolateral amygdala in the storage of fear memories across the adult lifetime of rats. J Neurosci 24:3810-3815.

Gentner T, Margoliash D (2003) Neuronal populations and single cells representing learned auditory objects. Nature 424:669-674.

Goosens KA, Hobin JA, Maren S (2003) Auditory-evoked spike firing in the lateral amygdala and pavlovian fear conditioning: mnemonic code or fear bias. Neuron 40:1013-1022.

Griffiths T, Warren J (2004) What is an auditory object? Nat Rev Neurosci 5:887-892.

Heil P (1997) Auditory cortical onset responses revisited. I. First-spike timing. J Neurophysiol 77:2616-2641.

Herzog C, Otto T (1997) Odor-guided fear conditioning in rats. 2. Lesions of the anterior perirhinal cortex disrupt fear conditioning to the explicit conditioned stimulus but not to the training context. Behav Neurosci 111:1265-1272.

Hobin JA, Goosens KA, Maren S (2003) Context-dependent neuronal activity in the lateral amygdala represents fear memories after extinction. J Neurosci 23:8410-8416.

Kimura A, Donishi T, Sakoda T, Hazama M, Tamai Y (2003) Auditory thalamic nuclei projections to the temporal cortex in the rat. Neuroscience 117:1003-1016. 
Knutson B, Burgdorf J, Panksepp J (2002) Ultrasonic vocalizations as indices of affective states in rats. Psychol Bull 128:961-977.

Koo JW, Han JS, Kim JJ (2004) Selective neurotoxic lesions of basolateral and central nuclei of the amygdala produce differential effects on fear conditioning. J Neurosci 24:7654-7662.

Kubvoy M, Van Valkenburg D (2001) Auditory and visual objects. Cognition 80:97-126.

LeDoux JE (2000) Emotion circuits in the brain. Annu Rev Neurosci 23:155-184.

Lee HJ, Choi JS, Brown TH, Kim JJ (2001) Amygdalar NMDA receptors are critical for the expression of multiple conditioned fear responses. J Neurosci 21:4116-4124.

Leung VL, Zhao Y, Brown TH (2006) Graded persistent firing in neurons of rat perirhinal cortex. Soc Neurosci Abstr 32:636.18.

Lindquist DH, Brown TH (2004) Temporal encoding in fear conditioning revealed through associative reflex facilitation. Behav Neurosci 118:395-402.

Lindquist DH, Jarrard LE, Brown TH (2004) Perirhinal cortex supports delay fear conditioning to rat ultrasonic social signals. J Neurosci 24:3610-3617.

Linke R (1999) Organization of projections to temporal cortex originating in the thalamic posterior intralaminar nucleus of the rat. Exp Brain Res 127:314-320.

Litvin Y, Blanchard DC, Blanchard RJ (2007) Rat 22kHz ultrasonic vocalizations as alarm cries. Behav Brain Res 182:166-172.

Maren S (2000) Auditory fear conditioning increases CS-elicited spike firing in the lateral amygdala even after extensive overtraining. Eur J Neurosci 12:4047-4054.

Maren S (2005) Synaptic mechanisms of associative memory in the amygdala. Neuron 47:783-786.

Maren S, Quirk GJ (2004) Neuronal signaling of fear memory. Nat Rev Neurosci 5:844-852.

McCormick DA, Thompson RF (1984) Cerebellum: essential involvement in the classically conditioned eyelid response. Science 223:296-299.

McCormick DA, Clark GA, Lavond DG, Thompson RF (1982) Initial localization of the memory trace for a basic form of learning. Proc Natl Acad Sci USA 79:2731-2735.

McGann JP, Brown TH (2000) Fear conditioning model predicts key temporal aspects of conditioned response production. Psychobiology 28:303-313

McGann JP, Moyer Jr JR, Brown TH (2001) Predominance of late-spiking neurons in layer VI of rat perirhinal cortex. J Neurosci 21:4969-4976.

Moyer Jr JR, Brown TH (2006) Impaired trace and contextual fear conditioning in aged rats. Behav Neurosci 120:612-624.

Moyer Jr JR, Brown TH (2007) Visually-guided patch-clamp recordings in brain slices. In: Patch-clamp analysis: advanced techniques for patchclamp analysis, Ed 3 (Walz W, ed), pp 169-228. Totowa, NJ: Humana.

Moyer Jr JR, McNay EC, Brown TH (2002) Three classes of pyramidal neurons in layer $\mathrm{V}$ of rat perirhinal cortex. Hippocampus 12:218-234.

Otto T, Cousens G, Herzog C (2000) Behavioral and neuropsychological foundations of olfactory fear conditioning. Behav Brain Res 110:119-128.

Padlubnaya DB, Allen TA, Brown TH (2006a) Perirhinal lesion effects on delay dear conditioning depend on stimulus features of the conditional stimulus. Soc Neurosci Abstr 32:67.14.

Padlubnaya DB, Parekh NH, Brown TH (2006b) Neurophysiological theory of kamin blocking in fear conditioning. Behav Neurosci 120:337-352.

Pare D, Quirk GJ, LeDoux JE (2004) New vistas on amygdala networks in conditioned fear. J Neurophysiol 92:1-9.

Paxinos G, Watson C (1998) The rat brain in stereotaxic coordinates, Ed 3. San Diego: Academic.

Pikkarainen M, Pitkanen A (2001) Projections from the lateral, basal and accessory basal nuclei of the amygdala to the perirhinal and postrhinal cortices in rat. Cereb Cortex 11:1064-1082.

Quirk GJ, Repa JC, LeDoux JE (1995) Fear conditioning enhances shortlatency auditory responses of lateral amygdala neurons: parallel recordings in the freely behaving rat. Neuron 15:1029-1039.
Quirk GJ, Armony JL, LeDoux JE (1997) Fear conditioning enhances different temporal components of tone-evoked spike trains in auditory cortex and lateral amygdala. Neuron 19:613-624.

Rauschecker JP, Tian B (2000) Mechanisms and streams for processing of "what" and "where" in auditory cortex. Proc Natl Acad Sci USA 97:11800-11806.

Repa JC, Muller J, Apergis J, Desrochers TM, Zhou Y, LeDoux JE (2001) Two different lateral amygdala cell populations contribute to the initiation and storage of memory. Nat Neurosci 4:724-731.

Romanski LM, LeDoux JE (1992) Equipotentiality of thalamo-amygdala and thalamo-cortico-amygdala circuits in auditory fear conditioning. J Neurosci 12:4501-4509.

Romanski LM, Averbeck BB, Diltz M (2005) Neural representation of vocalizations in the primate ventrolateral prefrontal cortex. J Neurophysiol 93:734-747.

Rutkowski RG, Miasnikov AA, Weinberger NM (2003) Characterisation of multiple physiological fields within the anatomical core of rat auditory cortex. Hear Res 181:116-130.

Sacchetti B, Lorenzini CA, Baldi E, Tassoni G, Bucherelli C (1999) Auditory thalamus, dorsal hippocampus, basolateral amygdala, and perirhinal cortex role in the consolidation of conditioned freezing to context and to acoustic conditioned stimulus in the rat. J Neurosci 19:9570-9578.

Sacchetti B, Baldi E, Lorenzini CA, Bucherelli C (2002) Differential contribution of some cortical sites to the formation of memory traces supporting fear conditioning. Exp Brain Res 146:223-232.

Sales G, Pye D (1974) Ultrasonic communication by animals. London: Chapman and Hall.

Schulz B, Fendt M, Richardson R, Schnitzler H-U (2004) Temporary inactivation of the perirhinal cortex by muscimol injections block acquisition and expression of fear-potentiated startle. Eur J Neurosci 19:713-720.

Shulz-Klaus B, Fendt M, Schnitzler H-U (2005) Temporary inactivation of the rostral perirhinal cortex induces an anxiolytic-like effect on the yohimbine-enhanced startle response. Behav Brain Res 163:168-173.

Sewell GD (1967) Ultrasound in adult rodents. Nature 215:512.

Shi CJ, Cassell MD (1997) Cortical, thalamic, and amygdaloid projections of rat temporal cortex. J Comp Neurol 382:153-175.

Shi CJ, Cassell MD (1999) Perirhinal cortex projections to the amygdaloid complex and hippocampal formation in the rat. J Comp Neurol 406:299-328.

Sokal RR, Rohlf FJ (1995) Biometry, Ed 3. New York: Freeman and Company.

Tankhiwale AA, Bang S, Allen TA, Boguszewski P, Brown TH (2007) Video analysis of unconditional and conditional freezing elicited by rat ultrasonic vocalizations. Annual Meeting of the Pavlovian Society, Austin, TX, October.

Tassoni G, Lorenzini CA, Baldi E, Sacchetti B, Bucherelli C (1999) A peculiar pattern of temporal involvement of rat perirhinal cortex in memory processing. Behav Neurosci 113:1161-1169.

Thompson RF (2005) In search of memory traces. Annu Rev Psychol 56:1-23.

Tian B, Reser D, Durham A, Kustov A, Rauscheker J (2001) Functional specialization in rhesus monkey auditory cortex. Science 292:290-293.

Tieu KH, Keidel AL, McGann JP, Faulkner B, Brown TH (1999) Perirhinalamygdala circuit-level computational model of temporal encoding in fear conditioning. Psychobiology 27:1-25.

van der Poel AM, Miczek KA (1991) Long ultrasonic calls in male rats following mating, defeat and aversive stimulation: frequency modulation and bout structure. Behaviour 119:127-142.

Weinberger NM (2004) Specific long-term memory traces in primary auditory cortex. Nat Rev Neurosci 5:279-290.

Yaniv D, Schafe GE, LeDoux JE, Richter-Levin G (2001) A gradient of plasticity in the amygdala revealed by cortical and subcortical stimulation, in vivo. Neuroscience 106:613-620.

Yaniv D, Desmedt A, Jaffard R, Richter-Levin G (2004) The amygdala and appraisal processes: stimulus and response complexity as an organizing factor. Brain Res Rev 44:179-186. 